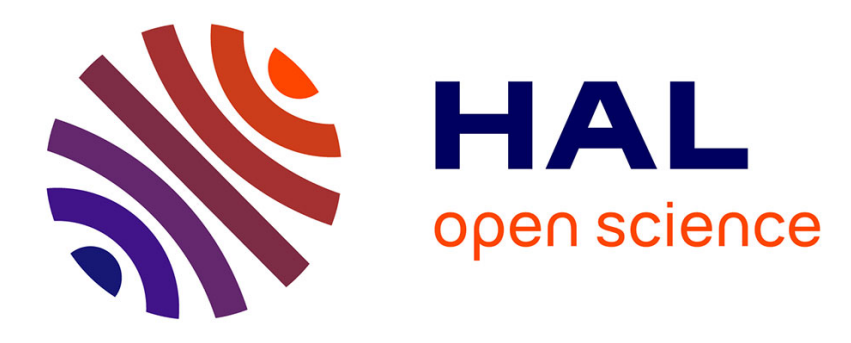

\title{
MORPHOGENESIS OF THE THYROID GLAND
}

Henrik Fagman, Mikael Nilsson

\section{To cite this version:}

Henrik Fagman, Mikael Nilsson. MORPHOGENESIS OF THE THYROID GLAND. Molecular and Cellular Endocrinology, 2010, 323 (1), pp.35. 10.1016/j.mce.2009.12.008 . hal-00593435

\section{HAL Id: hal-00593435 https://hal.science/hal-00593435}

Submitted on 16 May 2011

HAL is a multi-disciplinary open access archive for the deposit and dissemination of scientific research documents, whether they are published or not. The documents may come from teaching and research institutions in France or abroad, or from public or private research centers.
L'archive ouverte pluridisciplinaire HAL, est destinée au dépôt et à la diffusion de documents scientifiques de niveau recherche, publiés ou non, émanant des établissements d'enseignement et de recherche français ou étrangers, des laboratoires publics ou privés. 


\section{Accepted Manuscript}

Title: MORPHOGENESIS OF THE THYROID GLAND

Authors: Henrik Fagman, Mikael Nilsson

PII:

DOI:

S0303-7207(09)00616-9

Reference: $\quad$ MCE 7389

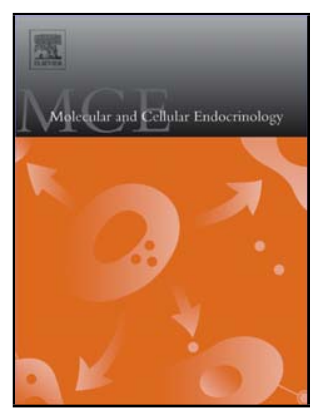

To appear in: $\quad$ Molecular and Cellular Endocrinology

Please cite this article as: Fagman, H., Nilsson, M., MORPHOGENESIS OF THE THYROID GLAND, Molecular and Cellular Endocrinology (2008), doi:10.1016/j.mce.2009.12.008

This is a PDF file of an unedited manuscript that has been accepted for publication. As a service to our customers we are providing this early version of the manuscript. The manuscript will undergo copyediting, typesetting, and review of the resulting proof before it is published in its final form. Please note that during the production process errors may be discovered which could affect the content, and all legal disclaimers that apply to the journal pertain. 


\section{MORPHOGENESIS OF THE THYROID GLAND}

Henrik Fagman $^{\mathrm{a}}$ and Mikael Nilsson ${ }^{\mathrm{b}}$

asstituto di Ricerche Genetiche "Gaetano Salvatore" (IRGS), Biogem scarl., Ariano Irpino, Italy

${ }^{b}$ Department of Medical Chemistry and Cell Biology, Institute of Biomedicine, Sahlgrenska

Academy at University of Gothenburg, Göteborg, Sweden

Address correspondence to: Henrik Fagman, $\mathrm{MD}, \mathrm{PhD}$

Istituto di Ricerche Genetiche "Gaetano Salvatore" (IRGS)

Biogem s.c.a.r.l.

Via Camporeale

83031 Ariano Irpino (AV)

Italy

e-mail: fagman@biogem.it 


\begin{abstract}
Congenital hypothyroidism is mainly due to structural defects of the thyroid gland, collectively known as thyroid dysgenesis. The two most prevalent forms of this condition are abnormal localization of differentiated thyroid tissue (thyroid ectopia) and total absence of the gland (athyreosis). The clinical picture of thyroid dysgenesis suggests that impaired specification, proliferation and survival of thyroid precursor cells and loss of concerted movement of these cells in a distinct spatiotemporal pattern are major causes of malformation. In normal development the thyroid primordium is first distinguished as a thickening of the anterior foregut endoderm at the base of the prospective tongue. Subsequently, this group of progenitors detaches from the endoderm, moves caudally and ultimately differentiates into hormone-producing units, the thyroid follicles, at a distant location from the site of specification. In higher vertebrates later stages of thyroid morphogenesis are characterized by shape remodelling into a bilobed organ and the integration of a second type of progenitors derived from the caudal-most pharyngeal pouches that will differentiate into C-cells. The present knowledge of thyroid developmental dynamics has emerged from embryonic studies mainly in chicken, mouse and more recently also in zebrafish. This review will highlight the key morphogenetic steps of thyroid organogenesis and pinpoint which crucial regulatory mechanisms are yet to be uncovered. Considering the coincidence of thyroid dysgenesis and congenital heart malformations the possible interactions between thyroid and cardiovascular development will also be discussed.
\end{abstract}




\section{INTRODUCTION}

\section{Congenital hypothyroidism}

Congenital hypothyroidism $(\mathrm{CH})$ is the most common disorder of the endocrine system among newborns. The incidence of $\mathrm{CH}$ affecting 1/3000-4000 is relatively constant globally (Toublanc, 1992), indicating that it is a distinct entity from hypothyroidism acquired by environmental influence as iodine deficiency. Irrespective of the cause, dwarfism and severe intellectual disability are the predominant features of children with untreated $\mathrm{CH}$. This underscores the fundamental importance of thyroid homeostasis for somatic growth and development of the central nervous system in the infant (Morreale de Escobar, 2001). Hence, delayed onset of thyroid hormone replacement therapy by only a few weeks after birth is associated with reduced development of mental functions later on in life (Klein et al., 1972). Fortunately, neonatal screening programs for early detection of $\mathrm{CH}$ have drastically improved the prognosis for these children which when properly substituted with thyroxin will reach the same intellectual capacity as matched control individuals including healthy siblings (Arnold et al., 1981). Nevertheless, there might still be a risk that $\mathrm{CH}$ with delayed onset due to thyroid hypoplasia is undiagnosed by neonatal screening. It is also evident that despite optimal treatment a subset of children with $\mathrm{CH}$ never develops normally due to the fact that the missing factor(s) of importance for normal thyroid organogenesis is required for the embryonic development of the brain and other organs independently of thyroid hormone (Krude et al., 2002). Moreover, congenital heart disease is overrepresented among children with thyroid dysgenesis, suggesting a developmental relationship between the thyroid and the cardiovascular system (Olivieri et al., 2002).

\section{Thyroid dysgenesis}

In approximately $15 \%$ of $\mathrm{CH}$ cases thyroid hormone production fails in a structurally normally developed gland. This condition, referred to as dyshormonogenesis, is due to autosomal recessive mutations of key molecules of thyroid hormone synthesis e.g. thyroperoxidase causing inborn errors 
of thyroid function. It is a relatively well-characterised entity of thyroid disorders and will therefore not be further discussed in this overview; for a recent review see (Park and Chatterjee, 2005). In the majority of children with $\mathrm{CH}$ the thyroid displays structural malformations. This constitutes a heterogeneous group of developmental defects with considerable phenotypic variations (Van Vliet, 2003). The most severe form is the complete lack of thyroid tissue named thyroid agenesis or athyreosis. The gland may also be smaller than normally. If it still has a normal position the condition is known as thyroid hypoplasia. If thyroid tissue has an aberrant location along the migratory path of the primordium it is called thyroid ectopia. From a pathophysiological point of view these conditions are collectively known as thyroid dysgenesis.

The prevalence of the different forms of thyroid dysgenesis varies depending on the diagnostic modality used for thyroid imaging. ${ }^{99}$ Tc scintigraphy is considered more sensitive than ultrasound to detect small remnants, although it requires that the thyroid tissue is terminally differentiated and accumulates the radioisotope (Kreisner et al., 2003). In a systematic scintigraphic survey of patients with permanent $\mathrm{CH}$ thyroid ectopia was found in $61 \%$, athyreosis in $16 \%$, hemiagenesis in less than $1 \%$ whereas $22 \%$ of the cases displayed a structurally normal or even hyperplastic thyroid (Devos et al., 1999). Similar numbers were detected in a study where the diagnosis was based on a combination of scintigraphy and ultrasonography. Interestingly, in this study thyroid ectopia was found only in $14 \%$ by ultrasonography indicating that small ectopic thyroids avoid detection and are instead classified as athyreosis. Nevertheless, ultrasonography likely provides a more precise assessment of thyroid morphology when the gland is in the normal location (Bubuteishvili et al., 2003). Hypoplasia of an orthotopic, bilobed gland has been reported to account for at most $5 \%$ of cases and thyroid hemiagenesis for less than 0.5\% (Van Vliet, 2003). As hemiagenesis is occasionally detected in asymptomatic individuals (Shabana et al., 2000; Korpal-Szczyrska et al., 2008) it could perhaps be questioned if it should really be included in the spectrum of disorders underlying $\mathrm{CH}$ (see below). 


\section{Normal thyroid development}

The thyroid gland in higher vertebrates is a composite organ formed by fusion of three anlagen that develop from the anterior foregut. The thyroid diverticulum from which the thyroid follicular cells derive emerges in the midline of the prospective pharynx close to the tongue base. The median anlage merges with a pair of lateral primordia, anatomically discussed as the ultimobranchial bodies (UB) that bring the parafollicular C-cells to the thyroid. This developmental process follows a sequence of morphogenetic steps that are similar in humans and mice, the most widely-used animal model of thyroid dysgenesis (De Felice and Di Lauro, 2007). Briefly, foregut endoderm cells specified to a thyroid fate first assemble as a placode in the pharyngeal floor. At the molecular level, these cells can be distinguished by the combined expression of a set of transcription factors: Nkx2-1 (formerly known as TTF-1), Foxe1 (formerly known as TTF-2), Pax8 and Hhex (Plachov et al., 1990; Lazzaro et al., 1991; Zannini et al., 1997; Thomas et al., 1998). As will be discussed in more detail below, these transcription factors play a fundamental role in the formation of the thyroid bud, but are also important for the functional differentiation of the gland in late development and postnatally. The growing midline thyroid primordium buds off from the pharyngeal floor and moves caudally along the anterior neck region. Thereafter, following bilateral expansion of the embryonic thyroid tissue, fusion with the UB takes place. Incorporation of the UB designates early lobe formation, whereas the mid-portion of the median primordium remains as the isthmus connecting the thyroid lobes across the midline. By this the final shape of the gland is established, accompanied by folliculogenesis and terminal differentiation of progenitor cells to hormone-producing thyrocytes that express thyrotropin receptor (TSHR), sodium-iodide symporter (NIS) and thyroglobulin (TG) (Lazzaro et al., 1991; Postiglione et al., 2002). Notably, as evidenced by genetic deletion experiments $\mathrm{TSH}$, the main regulator of thyroid function, does not participate in the embryonic morphogenesis and growth of the gland (Postiglione et al., 2002).

The causal events leading to thyroid malformations and $\mathrm{CH}$ in humans are in most cases unknown. The variable features of thyroid dysgenesis suggest multiple defects that interfere with 
fundamentally different developmental processes that regulate specification of thyroid progenitor cells, growth and relocalisation of primordia and bilobation, respectively, are involved. Here, we summarize by a temporal approach the current knowledge of key steps in thyroid morphogenesis and mechanisms of dysgenesis based on mainly experimental findings. When appropriate this will be discussed in the broader context of organ outgrowth along the embryonic gut tube and the molecules involved in endoderm patterning. We also try to identify unsolved issues of thyroid development that warrant further studies. For a detailed discussion on the genetics of thyroid dysgenesis in human patients with $\mathrm{CH}$ the reader is referred to excellent recent reviews (De Felice and Di Lauro, 2004; Castanet et al., 2007; Deladoey et al., 2007).

\section{ANIMAL MODELS OF THYROID DEVELOPMENT}

Research on thyroid development has traditionally been conducted mainly using the mouse (Fig. 1 and 3) and chick as experimental models. More recently, along with the growing awareness of the zebrafish as a powerful model system in developmental biology (Pyati et al., 2007), several novel mechanisms have also been discovered in studies on the zebrafish thyroid homologue (Fig. 2 and Table 1). However, although the biochemical machinery required for thyroid hormones synthesis is evolutionary well conserved and the basic structure of the thyroid functional unit, the follicles, is found in all vertebrates (Capen, 2000), there are distinct differences in thyroid anatomy among rodent, avian and fish species that need to be considered in comparative evaluations. Also the species-specific timing of key developmental steps needs to be taken into account when results from different organisms are discussed (Table 2) (O'Rahilly, 1983; De Felice and Di Lauro, 2004; Fagman et al., 2006; Alt et al., 2006b).

Of the three experimental animal models the gross anatomy of the adult mouse thyroid is most similar to the human gland. This is reflected also during embryonic development. Specifically, whereas the human and mouse thyroids are composite organs formed by the fusion of the midline primordium and the paired UB (Fagman et al., 2006) these structures remain separated in zebrafish 
(Alt et al., 2006b) and chicken (Kameda, 1995). In humans and mice calcitonin producing C-cells are therefore dispersed throughout the thyroid parenchyma whereas this cell type populates the ultimobranchial glands that persist as distinct organs in the chick and zebrafish final anatomy. The thyroid tissue proper is also differently organized in zebrafish, in which the follicles are not encapsulated but loosely disseminated along the ventral aorta in the lower jaw region without forming bilateral lobes as in the other species (Wendl et al., 2002) (Fig. 2F). However, the gross anatomical location of thyroid tissue in the neck or corresponding body segment is similar in tetrapods (e.g. human, mouse and chicken) and teleosts (e.g. zebrafish) (Kameda, 1995; Fagman et al., 2006; Alt et al., 2006a). Follicular cells in zebrafish also resemble thyrocytes of higher vertebrates in all other aspects, i.e. they express the orthologous transcription factors nk2-1a (Rohr and Concha, 2000) (see Fig. 2E), pax2.1, pax8 and hhex (Wendl et al., 2002) necessary for thyroid differentiation and produce TG (Alt et al., 2006b), accumulate iodine (Elsalini et al., 2003) and synthesise T4 (Wendl et al., 2002) (see Fig. 2G).

\section{ENDODERM ORIGIN OF THYROID PROGENITOR CELLS}

Already in the late $19^{\text {th }}$ century anatomists recognized the midline thyroid placode as an integral part of the pharyngeal epithelium (Tourneux and Verdun, 1897). However, it was only recently formally proven, by fate-mapping in zebrafish, that embryonic progenitors of the thyroid follicular cells stem from the definitive endoderm (Alt et al., 2006b). In comparison with other endoderm derivatives like the liver and pancreas very little is known about when and how a subset of endoderm cells adopts a thyroid fate. This question is by no means solely academic, since identification of the inductive molecules involved in thyroid specification will likely provide cues to novel pathogenetic mechanisms of thyroid dysgenesis. The following sections will therefore discuss these issues in more detail. 


\section{Specification and commitment of cell fate - general aspects}

To distinguish between different developmental events in the earliest stages of organogenesis some general definitions with special reference to the foregut and its derivatives need to be clarified. The initial commitment of distinct domains of endoderm towards a specific cell fate is designated regional specification, which implicates that groups of cells have a common destiny according to their position along the anteroposterior axis of the gut tube. Inductive signals control this process and the term competence signifies the ability of target cells to respond. A further distinction can be made between instructive signals that establish prospective organ identity and positional information to progenitor cells in the naïve endoderm and permissive signals that allow cell differentiation to progress along pre-determined, organ-specific developmental programs (Wells and Melton, 1999; Spagnoli, 2007). Committed endoderm subpopulations can be distinguished by both molecular and morphological characteristics. Markers of specification are often cellautonomous transcription factors that are expressed at the onset of primordium formation and throughout morphogenesis; in many endoderm derivatives including the thyroid such developmentally important factors also participate in the transcriptional regulation of organ function, illustrating their pleiotrophic mode of action (De Felice and Di Lauro, 2004). At the morphological level assemblies of progenitors can be distinguished due to the fact that the cells with a common fate become crowded and switch from a simple to a pseudostratified epithelium in restricted regions of the endoderm. The cells forming the thyroid placode in the anterior foregut endoderm co-express Nkx2-1, Foxe1, Pax8 and Hhex (Fig. 1A). However, as will be discussed in more detail later, although these transcription factors are obligatory for normal thyroid development none of them alone is required for early thyroid specification.

\section{Fate-mapping of thyroid progenitors in mouse endoderm}

Studies in mouse and to lesser extent chick embryos have provided important insights into which inductive signals and competence mechanisms specifically determine liver and pancreas 
development in the primitive foregut (Jung et al., 1999; Deutsch et al., 2001; Lee et al., 2005). For example, the expression of the forkhead transcription factors Foxa1 and Foxa2 are essential to make a subset of endoderm cells competent to adopt a liver fate (Lee et al., 2005). In contrast, nothing is presently known about specifying factors involved in determining the thyroid lineage before progenitors already can be identified at the placode and budding stages. To set the scene of this developmental process and understand what is of particular importance it is necessary to recapitulate some features of the early definitive endoderm.

In the early, pre-streak mouse embryo the epiblast is covered by extraembryonic visceral endoderm. During gastrulation, the definitive endoderm is formed by ingression of epiblast cells through the primitive streak. This will gradually displace the visceral endoderm to extraembryonic regions (to become part of the yolk sac) so that the early bud-stage embryo is covered on its external surface by definitive endoderm (Fig. 1B). Subsequently, this sheet of pluripotent cells remodels into the primitive gut that translocates to the interior of the mouse embryo coinciding with the turning of the entire embryo axis from a lordose (Fig. 1B) to the foetal position (Fig. 1D) (Wells and Melton, 1999; Lewis and Tam, 2006). Conversion of the endoderm sheet into a hollow tube requires extensive folding that is initiated by formation of the anterior and posterior intestinal pockets that open into corresponding anterior and posterior intestinal portals (AIP and PIP). This process is illustrated for the anterior part of the embryo in Fig. 1C, D. To close the gut tube along the anteroposterior axis the gut pockets elongate whereas the intestinal portals move towards each other. Eventually, ventral closure of the gut occurs by folding of the lateral parts of the endoderm (Lewis and Tam, 2006). From this it is evident that early organ development takes place in a highly dynamic environment in which the relative position of different endoderm domains that already at this stage are pre-patterned to distinct lineages of progenitors changes rapidly with respect to surrounding tissues and the orientation of the whole embryo.

It is presently unclear from which specific region of the endoderm mouse thyroid progenitors originate. However, a first clue was recently provided by fate-mapping after vital dye-labelling of 
small clusters of endoderm cells at the earliest somite stages (1-10 somites, corresponding to E8.0E8.25) prior to the expression of organ-specific markers (Tremblay and Zaret, 2005). This tracing approach has the clear benefit of being independent of tissue-specific promoter activation in already specified progenitor cells. In this way it was demonstrated that the liver bud forms by convergence of a ventral midline region of endoderm at the AIP lip and more lateral portions of the endoderm. Of potential interest to thyroid development, the midline portion of the AIP lip was found to also give rise to descendants that dispersed along the rostral-caudal axis of the embryonic midline (Tremblay and Zaret, 2005), possibly reaching as far rostrally as the region from which the thyroid is supposed to develop (Fig. 1C). According to another similar fate-mapping study the midline endoderm will sequentially form the floor, tip and roof of the anterior gut tube (Fig. 1B, D) (Franklin et al., 2008). Interestingly, the region of the ventral foregut corresponding to the presumptive thyroid placode seems to be derived from rostral midline endoderm present immediately caudal to the head fold and close to the cardiac crescent, whereas more caudal regions of midline endoderm will contribute to the dorsal foregut (Franklin et al., 2008) (Fig. 1C).

Similar movements of foregut endoderm domains have been described for avian embryos (Kirby et al., 2003). Moreover, in the early chick embryo Nkx2-1 is expressed in the ventral midline region of the AIP lip (Pera and Kessel, 1998). This could reflect the site of origin of the earliest specified thyroid precursors supporting the findings in mouse, although it should be kept in mind that Nkx2-1 expression is found also in lung bud progenitors. Employing a triple mouse transgenic approach the embryonic thyroid, thymus and peripheral parts of the lungs were found to originate from a shared pool of endoderm precursors before the respective cell lineages become restricted (Perl et al., 2002). However, as the lateral thyroid primordia that also express Nkx2-1 (Fagman et al., 2006) arise from the pharyngeal pouches located close to the thymus rudiment and lung bud it is conceivable that UB progenitors rather than those of the prospective midline thyroid anlage were detected by this fatemap. To summarize, the precise endoderm subdomain from which the mouse thyroid follicular 
progenitors originate and the critical factors responsible for thyroid fate commitment remain open questions that need to be elucidated.

\section{Fate-mapping of thyroid progenitors in zebrafish}

The topology of early endoderm development in zebrafish is different from that of the mouse embryo (Fig. 2A-E). The pharyngeal endoderm originates from the dorsal parts of the blastula whereas more posterior endoderm derives from the ventral blastula (Fig. 2C) (Warga and NussleinVolhard, 1999). Nevertheless, lineage-tracing has only recently formally confirmed that the zebrafish thyroid homologue indeed originates from the endoderm (Alt et al., 2006b). Specifically, this study showed that pre-labelled cells grafted very close to the shield in the dorsal hemisphere of the blastula contributed to the thyroid follicles that developed at later stages (Fig. 2C). By similar fate-mapping performed at the eight somite stage when the endoderm has not yet reached a position ventral to the neural tube by convergence, thyroid precursors were localized to the level of the midhindbrain boundary (Wendl et al., 2007). This is approximately at the same axial level as where markers of thyroid progenitors are first expressed in the endoderm. These important investigations in zebrafish have also established that the thyroid precursor region is close to hand2-expressing cells in the cardiogenic lateral plate mesoderm (Wendl et al., 2007). As discussed in more detail below, this may constitute a source of inductive signals for early thyroid development.

\section{Nodal signaling and early regulation of thyroid size}

At the molecular level, formation of the definitive endoderm and its further development in vertebrates are regulated by a well-conserved signaling network where members of the Nodal family play a superior role (Tam et al., 2003). Again, much of the signaling pathways have been elucidated in mouse and zebrafish embryo models. The crucial importance of Nodal signaling is evident in zebrafish mutants of the Nodal cofactor one-eyed-pinhead (oep) in which the endoderm is not specified and a gut tube fails to form. Consequently, no thyroid primordium can be found in 
this mutant (Elsalini et al., 2003). Considering the global effect of Nodal on endoderm development it can be anticipated that also mutations of downstream components of Nodal signaling affect thyroid morphogenesis. Indeed, the thyroid anlage is completely absent in cas and bon mutants (Elsalini et al., 2003), in which activation of Sox17, a downstream effector of Nodal crucial for the expression of endoderm specific genes is disrupted (Aoki et al., 2002; Tam et al., 2003; Sinner et al., 2004). It is probable that the thyroid phenotype merely is secondary to the global disturbance of endoderm formation rather than being thyroid-specific. However, thyroid specification may be more specifically sensitive to disruption of Nodal-signaling components, suggested by findings in zebrafish mutants of the GATA homologue faust (fau), which is a downstream target of Nodal that activates Sox17. In this mutant nk2.1 (the Nkx2-1 ortholog) expression is lost in the region of the prospective thyroid primordium whereas at the same time early gut tube formation is only mildly affected (Reiter et al., 2001). Notably, whereas ablation of Sox17 in mouse embryos leads to increased apoptosis in the foregut endoderm, specification and initial morphogenesis of the thyroid takes place also in the absence of Sox17 (Kanai-Azuma et al., 2002). This suggests that GATA signaling influences thyroid progenitors by additional mechanisms.

In cyclops $(c y c)$ mutants, targeting one of the zebrafish Nodal ligands, the thyroid primordium is specified but smaller than in wildtype embryos, presumably reflecting an overall reduction of pharyngeal endoderm (Elsalini et al., 2003). Intriguingly, in late thyroid development the number of follicles is reduced in this mutant. This suggests that the final thyroid size is constrained by the number of cells initially recruited to a thyroid fate. Other examples of development of thyroid hypoplasia associated with a reduced size of the early primordium are the hand 2 hypomorphic allele $\left(h a n^{\mathrm{c} 99}\right.$ ) and $f g f 8$ mutant (ace) in zebrafish (Wendl et al., 2007) and the Tbxl null mouse embryo (Lania et al., 2009), the effects of which will be discussed in further detail below. Direct evidence for this novel concept of developmental regulation comes from a recent study demonstrating that the number of progenitor cells in the pancreatic bud is limiting final organ size (Stanger et al., 2007). In contrast, embryonic liver growth seems to be able to fully compensate for 
a reduction of the hepatic progenitor pool, possibly reflecting the inborn regenerative capacity of the adult liver. Notably, in the absence of goitrogenous stimuli the thyroid regenerates poorly if a large portion is surgically excised (Clark et al., 1976). It may thus be speculated that a reduction of the precursor cell number initially specified might determine the total growth capability of thyroid tissue and the final size of the gland. Such a mechanism could possibly underlie thyroid hypoplasia as a cause of hypothyroidism (Van Vliet, 2003).

\section{POSITIONING OF THE THYROID PRIMORDIUM}

This section will discuss another aspect of early thyroid development, namely the anatomical localization of the definitive primordium and factors that are envisaged to play a decisive role. Formation of the mouse primitive gut tube is completed after turning of the embryo at approximately E8.5. At this stage the endoderm appears as a homogenous monolayered epithelium yet lacking obvious signs of specialization at the prospective sites of organ primordium outgrowth. However, the journey towards ultimate fate decision of pluripotent progenitors is initiated already as the definitive endoderm exits the primitive streak (Wells and Melton, 1999). The earliest recruited endodermal cells tend to contribute to the foregut whereas cells recruited later will preferentially occupy the mid- and hindguts (Lawson and Pedersen, 1987). The endoderm is thus probably loosely regionalized before the different organ buds start to develop along the anteroposterior axis of the gut. The mechanisms by which this positional identity of progenitor cells is established in the endoderm are largely unknown, although signals from adjacent embryonic tissues e.g. mesoderm and notochord appear to be important in restricting the emerging progenitor domains (Wells and Melton, 2000).

Mouse thyroid precursors come to populate a region of the ventral endoderm of the anterior foregut that anatomically forms the pharyngeal floor. So far no factors regulating the recruitment of cells to the prospective thyroid placode in mouse embryos have been identified. In zebrafish, retinoic acid (RA) impacts on the early regionalization of the endoderm and abrogation of RA signaling leads to 
posterior expansion of anterior cell fate. This influences also the position of the thyroid primordium, identified by nk2.1a and hhex expression, which is shifted posteriorly (Stafford and Prince, 2002). Increased RA activity, obtained by exposure to exogenously added RA, conversely results in an expansion of posterior endoderm cell fate. Interestingly, this is accompanied by a loss of the thyroid expression domain of hhex, supposedly due to a reassignment of positional identity (Stafford and Prince, 2002). These observations in zebrafish are most likely due to positional regulation of thyroid progenitors rather than being the result of altered thyroid fate of pluripotent endoderm. Also in mouse embryos, the thyroid primordium develops in a region of low endogenous RA activity indicated by the absence of Raldh2 expression and RA-reporter gene activation (Desai et al., 2004). In line with this, blocking of RA signaling in mouse embryo explants at a stage when initial patterning is already established does not influence the progression of early thyroid development, whereas at the same time RA-dependent lung bud induction is lost. Notably, in this situation the Nkx2-1 expression is markedly attenuated in the prospective lung bud but unaffected in the thyroid primordium (Desai et al., 2004). This suggests differential requirements of RA signaling for Nkx2-1 expression in these adjacent precursor fields.

In the chick embryo FGF-mediated patterning of the endoderm might be of relevance to thyroid positioning. FGF4 from the mesoderm regulates positional identity along the gut tube as indicated by the expression of Sprouty1/2 in the prospective hindgut. Exposure to exogenous FGF4 results in an anterior shift of these posterior markers and repression of Hhex and Nkx2-1 in the anterior endoderm (Dessimoz et al., 2006). Conversely, inhibition of the FGF receptor signaling pathway up-regulates and shifts Hhex posteriorly. As FGF2 and FGF8 are unable to reproduce this effect it is likely specific to FGF4. Since Hhex is required for the thyroid bud to develop normally (Martinez Barbera et al., 2000) FGF4 can thus possibly modulate the territory where thyroid progenitors assemble at least partly by regulation of Hhex.

Exclusion of morphogenetic signals may also be of importance for endoderm patterning and positioning of organ buds. One of the best examples is the locally repressed expression of Sonic 
hedgehog (Shh) in the endoderm region from which the dorsal pancreas bud forms. This is regulated by FGF2 and activin from the nearby notochord, which thus creates a boundary to pancreatic specification of pluripotent endoderm progenitors (Hebrok et al., 1998). The significance is illustrated by the fact that more widespread Shh repression leads to ectopic pancreatic differentiation (Kim and Melton, 1998) and that targeted over-expression of Shh in the prospective pancreas primordium partly diverts the lineage program of progenitors towards an intestinal fate (Apelqvist et al., 1997). That Shh might play a similar role in thyroid development by restricting the endoderm adopting a thyroid fate is suggested by the finding that Shh is strongly expressed in the adjacent foregut epithelium but not at all in the Nkx2-1-expressing progenitor cells forming the thyroid placode (Fagman et al., 2004; Parlato et al., 2004; Moore-Scott and Manley, 2005). However, the size of the early thyroid bud in Shh deficient mice is comparable to that of the wildtype anlage (Fagman et al., 2004; Parlato et al., 2004). Instead Shh may prevent ectopic differentiation of thyroid cells in more distant parts of the foregut and its derivatives as the prospective trachea (Fagman et al., 2004). The thyroid phenotype in Shh null mice as an animal model of thyroid dysgenesis will be further commented on below. Clearly, the exact role of Shh in thyroid development is far from completely understood. Notably, Shh is able to diffuse over considerable distances (Gritli-Linde et al., 2001) and although Shh is not expressed by endoderm cells committed to a thyroid fate these might still be targets of Shh morphogenetic signals since they express the Shh receptor Ptc1 (Washington Smoak et al., 2005). The importance of this morphogen as a key regulator of endoderm patterning and gut organogenesis has recently been excellently reviewed, highlighting the profound and diverse activities of Shh throughout embryonic development and beyond (van den Brink, 2007).

\section{INDUCTION OF A THYROID FATE}

Accumulating evidence indicates that the different endoderm cell lineages are induced by instructive signals from surrounding embryonic tissues. As already pointed out, the anterior foregut 
endoderm is in close apposition to the pre-cardiac mesoderm that gives a spatial foundation for reciprocal interactions (see Fig. 1D). By tissue recombination experiments it has for long been appreciated that that liver development depends on soluble factors produced by the cardiac mesoderm (Douarin, 1975; Gualdi et al., 1996; Rossi et al., 2001). Recently, induction of a liver cell fate was proven to be mediated by FGF1 and FGF2 from this source whereas subsequent outgrowth of the liver bud from the endoderm was dependent on FGF8 (Jung et al., 1999). As the thyroid primordium develops from pharyngeal endoderm in close proximity to the visceral mesoderm that forms the secondary heart field it is conceivable that thyroid inductive signals may originate there. Also, this opens up the possibility that athyreosis could be due to a variety of aberrations leading to disturbed juxtapositioning of the prospective thyroid field to the source of inductive signals or to inappropriate levels of these rather than to impaired function of a thyroid specific master-gene.

\section{Role of FGF and BMP signaling in early thyroid development}

In mouse explant co-cultures, cardiac mesoderm induces the expression of $\mathrm{Nkx} 2-1$ in ventral endoderm isolated at E7.5-8 (2-5 somites) (Serls et al., 2005). Also downstream targets of Nkx2-1 specific to the lung (surfactant protein C) and the thyroid (TG) are induced. As previously described for the liver (Jung et al., 1999), this capacity of cardiac mesoderm is reproduced by exogenous FGF1 or FGF2. Interestingly, the action is dose-dependent with lower FGF concentrations inducing liver genes like albumin whereas higher doses are required for Nkx2-1 expression. As FGF1 and 2 are able to induce Nkx2-1 also in dorsal midgut endoderm the signal seems to be instructive for a widespread domain of pluripotent endoderm progenitors (Serls et al., 2005).

The first direct evidence for a role of FGF in the induction of a thyroid fate comes from studies in zebrafish (Wendl et al., 2007). Exposure of early embryos to an inhibitor of FGF at a stage prior to specification leads to lack of thyroid primordium development without global defects in endoderm patterning. A similar phenotype is found in embryos mutant for the transcription factor hand 2 that has been suggested to be upstream of FGF (Abe et al., 2002). This effect is most likely non cell- 
autonomous to the thyroid but due to hand 2 activity in the cardiac lateral plate mesoderm juxtaposed to the thyroid anlage. Importantly, the thyroid phenotype in hand2 mutants is partly rescued by implantation of FGF $(1,2,8)$ soaked beads in close apposition to the endoderm. Importantly, the position of the rescued thyroid primordium is similar to that of wildtype embryos, suggesting a permissive rather than instructive role of the FGF signal that is downstream or in parallel to hand2. The importance of FGF signaling is further supported by the finding that ace mutants deficient for FGF8 display severely hypoplastic thyroid primordia (Wendl et al., 2007). This may correspond to the permissive role of FGF8 in liver morphogenesis after a liver fate has been induced in progenitor cells by FGF1 and FGF2 (Jung et al., 1999).

Recent work in mouse models has substantiated and further elaborated these findings. Disruption of the Shp2-binding sites of the FGF receptor (FGFR) docking protein FRS2 $\alpha$ causes thyroid hypoplasia (Kameda et al., 2009), indicating that embryonic thyroid growth is influenced by FGFR signaling. In view of the significant impact genetic deletion of $T b x 1$, a transcriptional regulator of FGFs (Vitelli et al., 2002), has on thyroid size in late morphogenesis (Fagman et al., 2007), early thyroid development was investigated in embryos where Tbxl was either generally deleted or specifically targeted in the mesoderm $\left(\right.$ Mespl $^{\mathrm{Cre} /+} ; \mathrm{Tb} x \mathrm{I}^{\mathrm{fl/}}$ ) (Lania et al., 2009). This showed that proliferation in the E8.5 foregut endoderm and the number of cells in the thyroid placode is reduced by mesodermal ablation of Tbxl suggesting a diminished thyroid precursor cell pool size. These effect are largely mimicked by deletion of $F g f 8$ in the Tbx 1 expression domain $\left(T b x 1^{\mathrm{Cre} /+} ; \mathrm{Fgff} \mathrm{fl}^{--}\right)$. Conversely, overexpression of $F g f 8$ from the $T b x l$ locus on a $T b x l$ deficient background $\left(T b x 1^{\text {Fgf8/- })}\right.$ rescues the thyroid size defect that is otherwise severely hypoplastic in Tbxl null embryos (Fagman et al., 2007). An FGF8 signal that depends on Tbx1 likely emanates from the mesoderm of the secondary heart field that is close to the thyroid primordium at early developmental stages. However, it is not yet clear if endodermal cells are the direct targets of this Fgf8 signal as deletion of FGFR1 and FGFR2 in the endoderm does not produce a thyroid defect (Lania et al., 2009). 
Taken together, studies in zebrafish and mice firmly establish that FGF signaling is crucial to early thyroid development and that the cardiac mesoderm is a probable source of inductive and permissive signals (Wendl et al., 2007; Lania et al., 2009). However, the exact role of FGF in early stages of thyroid development needs to be further clarified. This also accounts for Bone Morphogenetic Protein (BMP) signaling. BMPs and FGFs secreted from the septum transversum mesenchyme work in concert to promote competence of hepatic precursors as well as morphogenesis of the liver bud (Rossi et al., 2001). It remains to be elucidated whether BMPs play a similar role in early thyroid development. So far, the only indication in this direction comes from observations in mice deficient in Twisted, a context dependent modulator of BMP function. In Twisted null embryos the expression of Hhex is diminished in the liver primordium and cannot be detected in the presumptive thyroid primordium (Petryk et al., 2004). BMP might thus contribute to Hhex-dependent development of the thyroid bud (the role of Hhex will be further discussed below).

\section{Is thyroid morphogenesis coordinated with heart development?}

Cardiac defects are overrepresented among children with thyroid dysgenesis (Olivieri et al., 2002). This together with the close spatial relationship between the heart and thyroid primordial tissues suggest the possibility of common patterning traits in early morphogenesis. There are several observations of concomitant cardiac and thyroid defects also in experimental studies, supporting this notion. Zebrafish embryos deficient in FGF8 display both cardiac ventricle malformations (Reifers et al., 2000) and thyroid hypoplasia (Wendl et al., 2007). The action of FGF8 on heart development is probably mediated by the transcriptional activities of Nkx2.5 and GATA4 in responding cardiac progenitor cells (Reifers et al., 2000). Interestingly, Nkx2.5 is expressed in the pharyngeal endoderm encompassing the thyroid primordium (Biben et al., 2002) and Nkx2.5 mouse mutants exhibit a rudimentary thyroid along with the cardiac defect (Dentice et al., 2006). Moreover, certain GATA4 sensitive enhancer elements of the mouse $N k x 2.5$ gene are able to target 
expression specifically to both the heart and thyroid (Lien et al., 1999). This suggests that Nkx2.5 might be regulated by FGF8 also in thyroid progenitors.

Another example of a developmentally important transcription factor expressed in both thyroid and heart progenitor cells is Isl1 (Westerlund et al., 2008). Heart development is severely disturbed in Isl1 deficient mouse embryos involving defective reciprocal signaling between the cardiac mesoderm and the pharyngeal endoderm (Cai et al., 2003). The thyroid bud is smaller in Isll null mutant embryos (Westerlund et al., 2008). This may be the result of decreased cell survival in the pharyngeal endoderm that is normally supported by Isl (Cai et al., 2003). The mutant is embryonic lethal at E10.5 due to failure of the cardiovascular system to further develop. A possible additional role of Isl1 in thyroid organogenesis, as suggested by persisting expression of Isl1 in progenitor cells during migration of primordia (Westerlund et al., 2008), is presently not possible to appreciate. Nevertheless, these findings suggest that coincidental thyroid and heart malformations may arise in parallel by loss or otherwise impaired function of common signaling pathways. Alternatively, one structure could depend on correct signaling from the other for its early morphogenesis to proceed normally. Of particular interest, avian cardiogenesis is induced by anterior endoderm-derived signals (Schultheiss et al., 1995; Lough and Sugi, 2000), suggesting that reciprocal interactions between adjacent germ layers are important in the foregut region. Whether this involves the thyroid progenitor zone, which constitutes a relatively large portion of the endoderm facing the secondary heart field and the presumptive cardiac outflow tract, is an open intriguing question.

\section{A role of endothelial cells in early thyroid development?}

In addition to cardiac mesoderm much attention has been paid to the possible involvement of embryonic vessels and particularly endothelial cells as a source of inductive signals for endodermderived organs. The best examples of this are found in pancreatic and liver development. In a classical experiment, removal of the dorsal aorta located close to the emerging dorsal pancreas was found to block the expression of pancreas markers in the endoderm (Lammert et al., 2001). 
Furthermore, tissue recombination experiments showed that endothelial cells are able to induce a pancreatic fate in isolated endoderm (Lammert et al., 2001). Similar results were at the same time provided for liver organogenesis (Matsumoto et al., 2001). Together, this showed for the first time that vessels not only provide metabolic substances, but also play an active role in organ development. Using Flk1 deficient mice in which endothelial cells do not develop it has subsequently been demonstrated that initial pancreas induction occurs but emergence of the pancreatic bud fails (Yoshitomi and Zaret, 2004). Of note, the thyroid placode and the subsequent bud outgrowth are established in close contact with the aortic sac (Fagman et al., 2006). In fact, all Nkx2-1 positive thyroid progenitors assemble in the pharyngeal endoderm directly apposing the aortic sac endothelium before budding take place (Fig. 1A) (Fagman et al., 2006). This raises the question whether factors generated in the vessel wall or provided by the local circulation, as shown for the embryonic pancreas (Edsbagge et al., 2005), may influence early thyroid development as well. However, available experimental data clearly indicate that thyroid specification does not require a vascular signal. Specifically, in zebrafish Scl or vegf mutants in which the vascular patterning of the pharyngeal region including the thyroid specification zone of the endoderm is severely disturbed thyroid progenitors are readily specified (Alt et al., 2006a). In cloche mutants lacking all vascular progenitors of the anterior trunk the thyroid primordium is present (Alt et al., 2006a). That this also may account for the embryonic mouse thyroid is suggested by observations of a thyroid rudiment present in Tie2 mutants lacking endothelial cells (Postiglione and di Lauro, personal communication). As will be highlighted later on, the nearness to embryonic vessels is instead likely important for later stages of thyroid development (Alt et al., 2006a; Fagman et al., 2007).

\section{REGULATION OF THYROID BUDDING}

Assembly of thyroid progenitors in the pharyngeal endoderm is soon followed by budding of the primordium as a whole. Budding probably occurs concomitantly with the recruitment of new 
progenitor cells to the growing anlage (Smuts et al., 1978), signified by the thyroid placode becoming increasingly crowded with cells leading to a pseudostratified epithelium. As this process proceeds the thyroid bud, or diverticulum, forms a caudally protruding, cup-shaped evagination of the midline pharyngeal endoderm (Romert and Gauguin, 1973; Fagman et al., 2006) (Fig. 3A). Eventually, the descending bud detaches from the overlying endoderm by gradual thinning and disintegration of the thyroglossal duct, which thus is a transient embryonic structure.

Thyroid budding probably follows similar morphogenetic traits as other budding organs of the endoderm and it can be assumed that some common principles regarding the action of the regulatory molecules are at hand. However, unlike budding of e.g. the salivary glands, lungs and pancreas, which develop as iterative generations of branches maintaining physical contact with the region of primary bud emergence, the connection of the thyroid bud dissociates completely and rapidly from its site of origin. How bud detachment, shared also by the parathyroid and thymus primordia, is regulated is a yet largely unexplored aspect of thyroid development. Below is discussed what we know to date and what can be learned from studies on other budding organs.

\section{Proliferation versus recruitment of progenitors}

A locally enhanced proliferation of progenitor cells has been considered an important driving force for bud outgrowth in several primordial organs (Michael and Davies, 2004). Accordingly, the endoderm of the lung shows an increased proliferation rate (Goldin et al., 1984) which is evident once the bud is partially formed and not before (Nogawa et al., 1998). In contrast, an unexpectedly low proliferation rate characterizes the early thyroid primordium in mouse embryos, signified by the observation that both the placode and the emerging bud contain only few BrdU positive cells indicative of DNA synthesis (S-phase of cell cycle) as compared to the immediate neighbouring endoderm and adjacent mesoderm (Fagman et al., 2006). In fact, the fraction of cycling thyroid progenitors equals that of other highly proliferating tissues in the anterior embryo first when the primordium has detached from the endoderm and started migration. 
The cellular dynamics of thyroid bud formation has previously been studied in greater detail in chick embryos. Following $\left[{ }^{3} \mathrm{H}\right]$ thymidine incorporation it was demonstrated that the labelling index is significantly lower in the thyroid placode than in the adjacent endoderm (Smuts et al., 1978). The labelling pattern further suggested that the bud size expands by annexation of proliferating endoderm from outside the placode so that the central regions of the bud consists of the first integrated progenitor cells that display a lower rate of proliferation. The flow of cells from the periphery into the evaginating primordium has been further corroborated by detailed analysis of cell movements (Hilfer et al., 1990; Kinebrew and Hilfer, 2001). Together, data from mouse and chicken studies thus suggest that the endoderm portion engaged in the specification of thyroid progenitors is larger than that appreciated by the restricted expression of e.g. Nkx2-1 in the thyroid placode and early bud.

The mechanism of budding related to intraepithelial movements of proliferating precursor cells was recently investigated in the liver bud (Bort et al., 2006). This showed that the prehepatic epithelium becomes pseudostratified by a mechanism resembling asymmetric cell division originally identified in neuroepithelial cells (Gotz and Huttner, 2005). In this process called "interkinetic nuclear migration" cycling cells undergo S-phase when the nucleus has a more basal position and proceed into G2/M phase when the nucleus moves apically towards the luminal surface of the epithelium. The resulting cleavage at mitosis makes the daughter cells distribute asymmetrically relative to the plane of the epithelial sheet and, importantly, inherit apical and basal constituents that may reflect a first sign of differentiation towards distinct cell fates. A similar pattern was noticed for the liver, pancreatic and lung buds (Bort et al., 2006) suggesting that this may be a general feature of budding organogenesis in the endoderm.

Pseudostratification possibly involving interkinetic nuclear migration is also evident in thyroid placode and early bud formation. $\left[{ }^{3} \mathrm{H}\right]$ thymidine incorporation in the chick thyroid bud indicates that DNA synthesis occurs in the basal nuclear layers whereas mitosis is completed in the apical layers (Smuts et al., 1978). The mouse thyroid placode is also pseudostratified before the bud is 
formed. However, the essential lack of BrdU positive nuclei in mouse thyroid progenitors at the placode and budding stages (Fagman et al., 2006) does not clearly fit with the model of asymmetric cell division as a driving force of budding. Possibly, mouse thyroid precursor cells have passed through S-phase in a synchronized fashion before entering the placode and Nkx2-1 is expressed. That the initiation of thyroid bud morphogenesis probably is differently regulated than in the liver is further suggested from observations in Hhex null mouse embryos. In mutants the hepatic endoderm remains as a columnar, simple epithelium indicating that Hhex is required for interkinetic nuclear migration and liver bud formation (Bort et al., 2006). In contrast, although thyroid bud outgrowth fails the thyroid placode is readily pseudostratified in the absence of Hhex (Parlato et al., 2004). Irrespective of the mechanism, pseudostratification may be required but is not sufficient to initiate thyroid budding.

\section{Cytoskeletal remodelling}

Contraction of the cortical cytoskeleton present in the apical portion of epithelial cells is believed to generate a purse-string action that promotes bud morphogenesis (Wessells et al., 1971; Kiehart et al., 2000). This may be true also for the thyroid placode in which prominent cytoskeletal bundles are concentrated under the apical surfaces of the progenitor cells (Shain et al., 1972; Romert and Gauguin, 1973). Indeed, in vitro experiments on isolated foregut endoderm suggest that contraction of these bundles is a morphogenetic force that contributes to thyroid evagination (Hilfer et al., 1977). The significance of cytoskeletal modifications in budding processes is further supported by the finding that branching morphogenesis of the ureteric bud is inhibited by blocking the myosin activating Rho kinase ROCK (Michael et al., 2005). Recent results from real-time imaging indicate that the apical constriction of epithelial invaginations in Drosophila are more complex than a simple purse-string mechanism and involves pulsed contractions of an actin-myosin network that are stabilized by activity of the transcription factors snail and twist (Martin et al., 2008). Thus, cytoskeletal rearrangements participating in organ bud formation should be considered a highly 
coordinated event under the control of specific developmentally important regulatory signals. This further highlights the possibility that defective cytoskeletal regulation might be a novel mechanism of thyroid dysgenesis yet to be investigated.

\section{Role of Fgf10}

The molecular regulation of thyroid bud progression once initiated is largely unknown. However, since the thyroid and lung buds both express Nkx2-1 that is of crucial importance to further organ development, it is likely that at least partly shared mechanisms operate and that elucidation of a putative regulatory network in the thyroid may be inspired by present knowledge of embryonic lung morphogenesis. As recently reviewed (Kimura and Deutsch, 2007) this is controlled by an intricate network of endoderm- and mesoderm-derived signals comprising e.g. BMP4 produced by the endoderm tips of the lung buds and FGF10 secreted by the surrounding mesenchyme that act in concert to drive further budding and branching. Earlier studies on embryo explants have demonstrated that FGF10 is capable of inducing lung budding with only a modest effect on the proliferation of progenitor cells (Park et al., 1998). More recent expression analysis in the embryonic lung has shown that FGF10 induces genes associated with cell rearrangement and migration but not genes involved in cell cycle regulation (Lu et al., 2005). The possible relevance for thyroid development is suggested from studies on FGF10 in several transgenic mouse models; expression of a soluble, dominant-negative form of the preferred FGF10 receptor, FGFR2IIIb, causes agenesis or dysgenesis of a wide range of organs including the thyroid and the lungs (Celli et al., 1998) and FGF10 null mutant embryos lack both the thyroid and lungs (Ohuchi et al., 2000). However, a drawback is that in these studies only late embryos (E18.5) or newborns were analysed, which precludes any conclusions on the time window when FGF10 is required during thyroid morphogenesis or its mechanism. For example, FGF10 acts as a survival factor in developing epithelia (Sala et al., 2006) and lack of FGF10 might thus result in defective development due to increased cell death by apoptosis. Nevertheless, recent findings pointing out Nkx2-1 as a mediator 
of FGF10 morphogenetic signaling in the lung bud (Xing et al., 2008) is of particular interest as

Nkx2-1 is an early progenitor marker in both lung and thyroid. Interestingly, overexpression of FGF10 induces ectopic expression of $\mathrm{Nkx} 2-1$ and budding from the esophagus endoderm (Sakiyama et al., 2003), suggesting a mechanistic role in early development. The possibility that FGF10 in the thyroid primordium regulates Nkx2-1 therefore needs to be investigated.

\section{SURVIVAL AND GROWTH OF THYROID PROGENITORS DEPEND ON A THYROID- SPECIFIC SIGNATURE OF TRANSCRIPTION FACTORS}

The combined expression of Nkx2-1, Pax8, Foxe1 and Hhex is specific to the developing thyroid (De Felice and Di Lauro, 2004); although each of these transcription factors exerts distinct roles in other embryonic tissues it is only in thyroid progenitor cells they cooperate to drive organogenesis. Their importance is further emphasized by their impact on functional differentiation of follicular cells and regulation of thyroid-specific genes. Mice deficient of Nkx2-1, Pax8, Foxe1 or Hhex are well-studied models of athyreosis, i.e. the primordium is correctly specified but eventually regresses leading to a lack of thyroid tissue in late stages of development (Kimura et al., 1996; Mansouri et al., 1998; De Felice et al., 1998; Martinez Barbera et al., 2000). These transcription factors are thus not individually required for thyroid specification or early bud formation. Instead, experimental data suggests that progenitor cell recruitment and survival leading to enlargement of the thyroid bud depend on the concerted action of Nkx2-1, Pax8, Foxe1 and Hhex. $\mathrm{CH}$ patients with mutations of the respective genes have indeed been identified (De Felice and Di Lauro, 2004), albeit they seem to be relatively rarely occurring (Al Taji et al., 2007). Also germ line deletions of these transcription factors in animal models have provided important information on thyroid dysgenesis as a genetic disease. This will be summarized in the following paragraphs. 


\section{Nkx2-1}

Mice deficient of Nkx2-1 are stillborn due to pulmonary dysplasia (Kimura et al., 1996). The defect is related to the fact that $\mathrm{Nkx} 2-1$, as in the thyroid, is expressed in progenitor cells from the time of bud formation and onwards throughout lung development, regulating sequentially branching morphogenesis (Minoo et al., 1995) and alveolar maturation (Bohinski et al., 1994). The thyroid defect is also severe, as the thyroid bud is hypoplastic and regresses completely by E12-E13 (Kimura et al., 1999; Parlato et al., 2004). However, formation of the thyroid placode and subsequent pseudostratification of the early bud take place seemingly normally (Parlato et al., 2004), indicating that Nkx2-1 is required to complete budding. In zebrafish embryos loss of the Nkx2-1 ortholog $n k 2.1 a$ leads to disturbed thyroid development in a fashion similar to that demonstrated in the mouse mutant (Elsalini et al., 2003). The mechanism by which the thyroid primordium degenerates in the absence of Nkx2-1 has not been investigated in detail, although the presence of fragmented nuclei in Nkx2-1 deficient progenitor cells suggests involvement of an apoptotic process (Kimura et al., 1999). This possibility is supported by observations of an increased number of TUNEL positive cells in the UB epithelium deficient of Nkx2-1 (Kusakabe et al., 2006). It was also recently shown that inhibition of Nkx2-1 expression by RNAi induces decreased proliferation and increased apoptosis in lung cancer cell lines (Tanaka et al., 2007). Taken together, this suggests that Nkx2-1 is a cell-autonomous factor to thyroid and lung progenitor cells during development.

In humans Nkx2-1 haploinsufficiency gives rise to a syndrome characterized by thyroid hypoplasia, choreoathetosis and pulmonary disease (Krude et al., 2002; Pohlenz et al., 2002). The neurological symptoms cannot be rescued by thyroxin, illustrating the importance of Nkx2-1 transcriptional activity in forebrain development. Mice heterozygous for Nkx2-1 display mild hypothyroidism with elevated serum levels of TSH. Of interest, the thyroid phenotype of Nkx2-1 haploinsufficiency depends on the genetic background (Pohlenz et al., 2002). As will be further discussed below, this 
indicates the existence of modifier alleles that is also evident in thyroid dysgenesis may of polygenic origin (Amendola et al., 2005).

\section{Pax8}

Pax8 null mice are born at an expected Mendelian frequency but with a low body weight already at birth. Growth retardation becomes increasingly pronounced and only $20 \%$ of the pups survive until three weeks of age (Mansouri et al., 1998; Friedrichsen et al., 2003). T3 and T4 are undetectable (Friedrichsen et al., 2003) and TSH strongly elevated (Friedrichsen et al., 2004), indicating that these animals suffer from $\mathrm{CH}$. The cause of death is evidently hypothyroidism since Pax 8 mutants are rescued by supplementary thyroxin treatment (Friedrichsen et al., 2004). Thyroxin-substituted Pax8 deficient animals are nevertheless sterile, most probably due to a primary developmental defect in the reproductive system (Mittag et al., 2007; Wistuba et al., 2007).

The thyroid defect is similar to that of the Nkx2-1 knockout mouse as embryos lacking Pax8 show a normal thyroid placode (Parlato et al., 2004) but the bud is diminutive and by E12.5 thyroid progenitors can no longer be detected (Mansouri et al., 1998). The precise mechanism of thyroid dysgenesis in these animals is unknown but may involve loss of cells by apoptosis, as previously suggested (Parlato et al., 2004). Indeed, a protective role of $\operatorname{Pax}$ genes against apoptosis is suggested from in vitro studies of tumour cells (Muratovska et al., 2003). The mild extra-thyroidal phenotype makes the Pax 8 null mutant an attractive animal model for further investigation of the molecular and cellular mechanisms leading to athyreosis by regression of the thyroid bud and $\mathrm{CH}$. Pax 8 is also a preferable thyroid marker to experimentally distinguish progenitors destined to a follicular fate; the other three transcription factors (Nkx2-1, Foxe1 and Hhex) are in addition expressed in other regions of the endoderm, the UB and the lung bud.

Zebrafish orthologs of the pax2/5/8 paralog group are also crucial to thyroid development. Pax 8 and pax2.1 are coexpressed in the thyroid anlage, and the thyroid gland is absent even though specification does occur in pax2.1 mutants (noi) (Wendl et al., 2002). In the mouse deletion of Pax2 
does not affect thyroid development (Wendl et al., 2002). Pax2.1 may thus hold a role in zebrafish thyroid development similar to that of Pax8 in the mouse.

In humans heterozygous $\operatorname{Pax} 8$ mutations are occasionally identified in $\mathrm{CH}$ patients with variable thyroid phenotypes, mostly characterized by hypoplasia of the gland (Macchia et al., 1998).

\section{Foxe1}

Foxe1 deficient mice are born at an expected ratio but die in the early postnatal period, probably due to the severe cleft palate (De Felice et al., 1998). No orthotopic thyroid is present and hormone analysis reveals severe $\mathrm{CH}$. In early thyroid morphogenesis a rudimentary bud is formed but its fate is variable: in $50 \%$ of the embryos the thyroid bud retains a position at the base of the prospective tongue, present also in late development (E15.5), whereas in the remainder cases no thyroid is found at all. It has therefore been proposed that Foxe1 specifically regulates the migration of the mouse thyroid primordium after detachment of the bud, besides supporting progenitor cell survival (De Felice et al., 1998), which will be discussed in further detail below (migration section). In contrast, no thyroid phenotype has been identified after knock-down of a recently characterized zebrafish Foxe1 ortholog (see below) (Nakada et al., 2009). The variable phenotype of the Foxe1 knockout is interesting, considering the fact that athyreosis and ectopia may be present among relatives in familiar forms thyroid dysgenesis (Castanet et al., 2001). Even though the mechanism in these cases might not directly involve Foxe1, this suggests that different thyroid malformations may share a common primary genetic cause (Castanet et al., 2001). Homozygous Foxe1 mutations have been identified as a likely causal event in two pairs of siblings with the Bamforth-Lazarus syndrome in which $\mathrm{CH}$ due to athyreosis is a prominent feature (Clifton-Bligh et al., 1998).

\section{Hhex}

Reflecting the widespread expression of Hhex in early organogenesis Hhex null mouse embryos show multiple malformations and are not viable after E15.5. Most strikingly, the liver is absent and 
the forebrain is truncated, the severity of which grades the phenotype from I (severe) to III (mild). In the initial description of class I Hhex mutants Nkx2-1 and Foxe1 expression were missing in the endoderm of the prospective te thyroid primordium (Martinez Barbera et al., 2000), suggesting that Hhex might play a role in thyroid specification. However, it should be noted that these embryos display a general deficiency in anterior endoderm (Martinez Barbera et al., 2000) and the defect is therefore likely not thyroid specific. Thyroid specification readily occurs in type II and III mutants, although the primordium is severely hypoplastic and the cells do not organize into a distinct bud (Parlato et al., 2004). Hhex is thus required for thyroid bud formation and likely also influences the survival of progenitor cells. Whether this is due to a direct action of Hhex on target genes or is mediated by Pax 8 and Foxe1, that are down-regulated in the absence of Hhex (Parlato et al., 2004) (see discussion below), is currently not clear.

In zebrafish depleted of hhex thyroid specification occurs but further development fails (Elsalini et al., 2003), similar to the mouse phenotype. The developmental stage and mechanism by which this defect occurs are yet to be demonstrated. Of particular interest, late thyroid development is influenced by hhex dosage in zebrafish, i.e. overexpression of hhex increases the final size of the gland (Elsalini et al., 2003). As the thyroid placode in this situation was found not to be enlarged, this suggests that hhex regulates cell proliferation after the pool of endoderm progenitors destined to a thyroid fate has been specified. This is of fundamental interest taking into account the recent findings in mouse that the number of progenitors that populates the placode determines the embryonic thyroid size and is controlled by Tbx1 expressed in the mesoderm (Lania et al., 2009). Hhex thus appears to be a regulator of thyroid size in later stages of organogenesis, at least in zebrafish.

\section{Nkx2-1, Pax8, Foxe1 and Hhex form a regulatory network in thyroid progenitor cells}

Dissecting the individual roles of Nkx2-1, Pax8, Foxe1 and Hhex in thyroid development is complicated by the fact that they form a network of reciprocal cross-interactions. This probably 
occurs both at the level of promoter binding and by physical interaction with the other transcription factor(s). In vitro data demonstrate that binding sites and transactivating capacity of Nkx2-1 (Puppin et al., 2003) and Pax8 (Puppin et al., 2004) are present in the Hhex promoter. Pax8 interacts physically with Nkx2-1 (Di Palma et al., 2003) and activates the transcription of Foxe1 (D'Andrea et al., 2006). In addition, Hhex (Puppin et al., 2003) and Nkx2-1 (D'Andrea et al., 2006) autoregulate their own promoters. The relevance of this transcriptional network to thyroid development has been demonstrated in both mouse (Parlato et al., 2004) and zebrafish (Wendl et al., 2002; Elsalini et al., 2003). Interestingly, the transcriptional regulation appears to change as the thyroid primordium progresses from one developmental stage to another (Parlato et al., 2004). In the placode, when either one of Nkx2-1, Pax8 or Hhex is deleted the expression of the other two transcription factors remains unaltered; only Foxe1 is already at this stage under the control of Pax 8 (Parlato et al., 2004). However, when budding proceeds both Foxe1 and Hhex are down-regulated in Nkx2-1 or Pax8 deficient embryos and the expression of Pax8 and Foxe1 is lost in Hhex null embryos (Parlato et al., 2004). Foxe1 seemingly holds a lower position in this network since the expression of the other transcription factors maintain in Foxel deficient progenitors (De Felice et al., 1998; Parlato et al., 2004). The interdependence of $N k x 2-1, \operatorname{Pax} 8$ and Hhex makes it difficult to determine whether the disappearance of the thyroid bud in mutant embryos reveals a direct regulation of cell proliferation or survival mechanisms by the individual factor or if the effect is secondary to loss of function of one or more other components of the network.

Several lines of evidence suggest that a similar network of cell-autonomous transcription factors regulate thyroid development in zebrafish. Thyroid specification occurs when either $n k 2.1 a$, hhex (Elsalini et al., 2003) or pax2.1 (Wendl et al., 2002) are deleted, signified by the expression of the other factors in progenitor cells. However, although hhex and pax 2.1 are initially not affected when nk2.1a is knocked down both factors subsequently disappear, suggesting a requirement of nk2.1a for their sustained expression (Elsalini et al., 2003). Likewise, in pax2.1 mutant embryos nk2.1a and hhex are expressed in the thyroid placode but in later development both markers are lost 
(Wendl et al., 2002). A time-dependent loss of nk2.1a and pax2.1 also characterizes the thyroid primordium deficient of hhex (Elsalini et al., 2003). If these findings in zebrafish reflect a direct regulation by one factor of the others at later stages of development or merely is the result of the disappearance of thyroid tissue is not clear. The advantages of the zebrafish as an experimental tool and the apparent conservation of the regulatory network make it an attractive model for further studies of these molecular interactions in thyroid development. However, when comparing data from mouse and zebrafish it should be kept in mind that the temporal progression of thyroid morphogenesis and functional differentiation is clearly different between these species. In the mouse growth of primordial cells occurs for several days and the final shape of the gland is manifest before differentiation towards a mature thyrocyte phenotype is evident. In contrast, functional differentiation is rapid and largely precedes growth of the thyroid primordium in the zebrafish. This probably reflects the demand of zebrafish embryos to become independent of maternal thyroid hormone supply already in early development (Elsalini et al., 2003).

\section{EMBRYONIC THYROID MIGRATION - ACTIVE, PASSIVE OR BOTH?}

The developing thyroid in higher vertebrates undergoes a significant change in position, from the site of origin at the base of the prospective tongue to the inferior neck at the level of the larynx and proximal trachea. This process is generally described as migration of the thyroid primordium (Fig 3B). A corresponding translocation takes place in zebrafish embryos although the thyroid tissue does not assemble into an encapsulated organ (Alt et al., 2006a). In the human fetus defective or incomplete caudal movement of the thyroid may be responsible for several clinically important conditions, e.g. an ectopic lingual thyroid or thyroglossal duct cysts (Sprinzl et al., 2000). Whether embryonic thyroid migration is an active process involving cell-autonomous mechanisms decisive for a migrating phenotype of the individual thyroid progenitor cells or merely reflects a positional change secondary to the growth and gross rearrangement of adjacent tissues and structures in the 
anterior part of the embryo is a matter of debate. Although not necessarily mutually exclusive, possible mechanisms of active or passive movement will be discussed separately in the following.

\section{Arguments favoring active migration of thyroid progenitor cells}

Epithelial cells typically acquire migrating capacity by activation of distinct signaling pathways and gene expression changes leading to epithelial-to-mesenchymal transition (EMT), a phenomenon commonly recognized in embryonic development (Baum et al., 2008). EMT is characterized by the adoption of a spindle-shaped morphology and a switch in the expression of cadherin adhesion molecules. Down-regulation of E-cadherin has thus been linked to the induction of EMT whereas neoexpression of $\mathrm{N}$-cadherin promotes the acquisition of an invasive phenotype (Wheelock et al., 2008). In thyroid development, when the bud disconnects and migrates caudally, the thyroid progenitors move as a coherent group of seemingly tightly connected cells that retain an epithelial shape (Fagman et al., 2006) (Fig. 3A, B). In fact, the expression of E-cadherin is maintained throughout all stages of thyroid morphogenesis, and the cells do not ever express N-cadherin (Fagman et al., 2003). Together, this strongly argues against the involvement of EMT in embryonic thyroid migration. However, this does not rule out that individual progenitor cells participate in the process by active migration. In fact, the concept of collective cell migration, implicating that firm cell-to-cell adhesion does not impair but on the contrary is a prerequisite for the movement of groups of cells, has gained increasing attention (Friedl and Gilmour, 2009). An illustrating example of this kind of migration is the relocalisation process of border cells during Drosophila oogenesis. These cells delaminate from the anterior follicular epithelium and migrate posteriorly as a coherent cluster towards the oocyte. Genetic analysis combined with live imaging have revealed that each cell of the cluster reads out the gradient of an attracting guidance cue but that the direction of movement is encoded by the collectively generated net vector of the cluster (Rorth, 2007; Bianco et al., 2007). By this attractive model follows that adhesion is not a constraint for migration but is instead necessary to transmit the net vector of directed movement to the trailing cells and prevent 
the cluster from tearing apart (Friedl and Gilmour, 2009). The observation that the thyroid bud, after it has pinched off from the endoderm, has a leading edge that points in the migration direction towards the descending aortic sac (Fagman et al., 2006) is compatible with the idea that collective migration might apply also to the embryonic thyroid.

The strongest argument in favor of active cell migration in thyroid morphogenesis comes from studies on Foxel mutant mouse embryos in which the thyroid bud is either absent or remains contiguous with the pharyngeal endoderm (De Felice et al., 1998). Still, evidence that this is due to a cell-autonomous, direct function in thyroid cell migration has been lacking. However, a recent study provides proof in the direction of such a role of Foxel in the detachment and caudal movement of the bud (Parlato et al., 2004). By knock-in of Foxel into the Nkx2-1 locus of Foxe1 deficient mice a role of Foxel that is expressed in the adjacent endoderm could be ruled out but instead that the observed rescued thyroid phenotype depends on Foxe1 expressed in the thyroid primordium itself. Formally, this does not exclude the possibility that Foxe1 is critical at a stage immediately preceding an actual migration process. For example, Foxe3 is necessary for the separation of the lens vesicle from the ectoderm of the prospective cornea (Blixt et al., 2000; Medina-Martinez et al., 2005), suggesting a more general function of Foxe members in the delamination of budding epithelia during embryogenesis. It is thus possible that Foxe1 primarily regulates the growth and detachment of the thyroid bud from the endoderm whereas further movement relies on non cell-autonomous morphogenetic mechanisms. Nevertheless, irrespective of the mechanism Foxe1 likely generates a cell-autonomous signal, by activating yet unknown target genes, which either is permissive to or directly execute embryonic thyroid migration in higher mammals.

In this respect it is interesting to shortly comment on Foxe1 from a phylogenetic point of view. The Ci-FoxE gene of Ciona intestinalis and the amphioxus AmphiFoxE4 gene have been considered ancestral to Foxe1, Foxe 2 and Foxe3 in higher vertebrates (Yu et al., 2002) even though this notion has recently been questioned (Nakada et al., 2009). FoxE genes are expressed in the thyroid 
homolog of the adult endostyle that remains contiguous with the pharyngeal endoderm (Ogasawara and Satou, 2003; Hiruta et al., 2005). It has therefore been hypothesized that a function of a FoxE gene arose in the endostyle already in urochordates to regulate thyroid specific gene expression before a putative morphogenetic function developed (Hiruta et al., 2005). In Xenopus, a FoxE1 gene homologous to murine Foxel is expressed in the presumptive pituitary and thyroid that later buds off from the maternal germ layer (El-Hodiri et al., 2005). Following a gene-duplication event, Foxel has thus been suspected to have acquired an additional, morphogenetic role in higher vertebrates to promote migration of the developing thyroid. It should be noted though that a Foxe1 ortholog (foxe1) in zebrafish was recently described and found to be expressed in the pharyngeal endoderm and developing thyroid. However, unlike mouse Foxe1 null embryos knock-down of zebrafish foxel caused no alteration of thyroid morphology but other craniofacial defects. The authors suggest that the role of Foxe1 in mammalian thyroid morphogenesis might have been acquired during evolution or that a foxel paralog or other foxe genes possibly compensate for loss of foxel function in zebrafish thyroid development (Nakada et al., 2009).

\section{Positional change of the thyroid primordium due to differential growth of surrounding tissues}

An alternative mechanism to active migration of progenitor cells is that the thyroid primordium shifts position as a consequence of differential growth of adjacent embryonic tissues and the overall elongation of the neck. By this follows that after delamination only the relative position of the embryonic thyroid would change as it thus passively moves in a caudal direction with respect to the position of its point of evagination. Support of this possibility was provided in earlier studies in chick embryos in which the dispersion pattern of beads implanted around the thyroid bud was studied (Knospe et al., 1991). However, as all structures of a body that are not attached to the surface seem to move away from it as the body expands it is difficult from a methodological point of view to elucidate what is actually moving. The principle could be illustrated by placing two marks on an elastic cord and pulling the ends. This causes the marks to move apart, not as a 
consequence of migration, but secondary to elongation of the cord. Recently, use of more stable, centrally located reference points in computerized reconstructions of serially sectioned embryonic tissues have been used to overcome this problem. Applying this approach it has been proposed that the positional change of the thyroid during development depends on differential growth of the embryo as a whole rather than on active migration (Gasser, 2006). The fact that patients with ectopically located sublingual thyroid mostly have a normal neck anatomy might be taken as an argument against a contribution of this mechanism. However, as pointed out before a sublingual thyroid may be due to a failure of the bud to correctly dissociate from the pharyngeal floor rather than indicating a true migration defect.

\section{Thyroid movement related to remodeling of embryonic vessels}

The thyroid primordium is closely associated with the aortic sac, representing the distal segment of the embryonic cardiac outflow tract (OFT), when it progresses through the budding and migration stages (Fagman et al., 2006). When OFT is transposed into the thoracic cavity as the heart assumes its final position this offers a potential "piggyback" mechanism by which the embryonic thyroid is carried or rather pulled downwards the neck to the level where bilobation later occurs (see Fig. 3A, B). In fact, a relationship between thyroid migration and the development of the cardiovascular tree was proposed already by the 1980s by Hilfer and Brown (Hilfer and Brown, 1984). The hypothesis is supported by the occasional reports of ectopic thyroid tissue present in or close to the heart and ascending aorta (Casanova et al., 2000; Williams et al., 2002). It is assumed that this represents thyroid progenitors that are carried into the thoracic cavity by the retracting OFT. In contrast, ectopic thyroid tissue occasionally found in abdominal locations (Strohschneider et al., 1993; Eyuboglu et al., 1999; Shiraishi et al., 1999; Gungor et al., 2002; Venditti et al., 2007) likely arise by metaplasia of mostly endoderm derived epithelia in adult life and thus unrelated to embryonic movement of thyroid progenitors. As will be discussed in more detail concerning the mechanisms of thyroid bilobation, mouse and zebrafish mutants with defective cardiovascular development also 
present a thyroid phenotype (Alt et al., 2006a; Fagman et al., 2007). Moreover, a possible association between heart and thyroid is illustrated by the clinical association of cardiac malformations and thyroid dysgenesis (Olivieri et al., 2002). It should be noted, however, that most patients with a sublingual thyroid suggestive of a migration defect do not display overt cardiac defects and when investigated display no anatomical anomalies of the heart and great vessels (Olivieri et al., 2002; Al Taji et al., 2007). If pathogenetic, impaired interaction with vessels therefore must be subtle, affecting further development only of the thyroid.

\section{LATE THYROID MORPHOGENESIS - THE BILOBATION PROCESS}

In the mouse embryo the median and lateral thyroid anlagen undergo major morphogenetic rearrangements between E12-14, which leads to the definitive shaping of the gland characterized by left and right lobes connected across the midline by the isthmus portion (Fig. 3E). The sequence of events has been thoroughly investigated (Fagman et al., 2006). By E12.5 the growing median primordium has adopted the shape of a horizontal bar that follows the course of the third pharyngeal arch arteries (Fig. 3C). Subsequently, the distal ends of the primordium approach the paired UB, and starting at E13.5 these tissues gradually coalesce by which the UB are overgrown and eventually enclosed by the thyroid progenitors destined to a follicular fate (Fig. 3D, E). Both primordial tissues thus contribute to the prospective thyroid lobes. The apparent precision by which the anlagen find each other from first being widely separated both in the transverse plane and along the anteroposterior axis of the embryo (Fagman et al., 2006) suggests that fusion is a finely regulated process, presumably involving mutually attractive forces. Supporting this notion, embryos deficient of Hox genes or Pax3 show defective thyroid bilobation along with lack of fusion or agenesis of one or both UB (Franz, 1989; Manley and Capecchi, 1995; Manley and Capecchi, 1998). Also, in a model of defective FGF signaling the lack of one thyroid lobe is prevalent and frequently associated with the lack of a UB on the ipsilateral side (Kameda et al., 2009). Yet, fusion of the midline thyroid and the UB does not seem to be necessary for bilobation to occur. In chick 
embryos the UB develop into distinct organs, the ultimobranchial glands that remain separated from the thyroid primordium throughout morphogenesis and later. Still, the chick thyroid has two lobes, that are widely separated and not connected by an isthmus (Kameda, 1995). In the turtle on the other hand, the thyroid has the shape of a single, unlobulated disc located in the midline close to the aortic arch whereas UB are present bilaterally (Clark, 1971). Deletion of Pax9 leads to impaired UB formation in early mouse development (Peters et al., 1998) but mutants have no thyroid bilobation defect (H Peters, personal communication). From this it can be concluded that the UB in higher vertebrates provide the thyroid with C-cells (to be discussed in a following section) but likely do not have a key role in the bilobation of the gland.

\section{Clinical features of thyroid hemiagenesis}

Thyroid hemiagenesis, meaning absence of one lobe, is occasionally detected among asymptomatic individuals; prevalence figures from 0.05\% (Maiorana et al., 2003; Korpal-Szczyrska et al., 2008) to $0.2 \%$ (Shabana et al., 2000) have been reported. Interestingly, hemiagenesis almost invariably affects the left lobe, suggesting a specific developmental cause rather than a stochastic mechanism. In this condition thyroid hormone levels are usually within the normal range, although a significant increase in TSH as compared to matched controls was recognized in the largest cohort of patients with hemiagenesis (Maiorana et al., 2003). This study further showed that hypertrophy of the remaining lobe is frequent. However, compensatory growth does not always seem to be sufficient, since cases of overt hypothyroidism have been reported (Devos et al., 1999). Thus, incidentally diagnosed thyroid hemiagenesis should likely prompt an increased awareness of disturbed thyroid function later in life (Maiorana et al., 2003). That hemiagenesis should be considered a variant of dysgenesis is indicated by the finding of a familial association with other developmental malformations as ectopic thyroid and athyreosis (Castanet et al., 2005). This observation further suggests that different types of thyroid dysgenesis might share a common pathogenetic mechanism producing a variable phenotype. Possibly, a putative second factor(s) acting in a limited but critical 
spatiotemporal window during development has the capacity to drastically alter the final outcome of morphogenesis. Identification of factors regulating thyroid bilobation will thus likely provide general insights into the pathogenesis of thyroid dysgenesis.

\section{Embryonic vessels may act as guiding tracks for bilateral thyroid growth}

The development of the final thyroid shape is likely influenced by the growing trachea (and the oesophagus behind) that projects ventrally in the midline. This puts pressure on the isthmus reinforcing its narrow horseshoe-shape that is apparent in transverse sections (Knospe et al., 1991). However, in the earliest stage of bilobation bilateral growth of the thyroid primordium takes place with yet no close spatial relation to the prospective trachea. Instead, after the thyroid descent is completed the primordium elongates horizontally along the route of the paired third pharyngeal arch arteries (Fig. 3C) (Fagman et al., 2006; Alt et al., 2006a). Of particular interest, the proximal parts of these vessels contribute to the segment of the carotid arteries that pass, in the final anatomy, immediately lateral to the mature thyroid lobes (Capen, 2000) (Fig. 3C-E). It has therefore been proposed that arch arteries serve as guiding tracks for thyroid progenitors as they proliferate and migrate towards the UB (Fagman et al., 2006). According to this model bilobation requires both a normal embryonic vessel anatomy and direct interaction between the vessel and the thyroid primordium. This possibility has been directly addressed in the zebrafish model in which the influence of ectopic vascular cells on thyroid morphogenesis was investigated (Alt et al., 2006a). The zebrafish thyroid is normally dispersed as an elongated strand of separated follicles along the ventral aorta (see Fig. 2F, G). Ectopic endothelium implanted in the pharyngeal mesenchyme induced a directed migration of thyroid progenitors towards the grafting site. Furthermore, in vegf, $f l k l(k d r)$ and $s c l$ mutants, which all show disturbed pharyngeal vasculogenesis, the thyroid was mislocalised and irregularly distributed around the cardiac outflow tract (Alt et al., 2006a). Taken together, this strongly suggests that vessels provide guidance cues in zebrafish thyroid morphogenesis. 
Genetic studies in mouse support a morphogenetic role of the embryonic vascular anatomy in late thyroid development. In Shh deficient embryos, which have asymmetric pharyngeal and carotid vessels, bilobation fails and the thyroid persists as an undivided mass on one side of the neck (Fagman et al., 2004; Alt et al., 2006a). This is of fundamental interest because Shh is not expressed in the median thyroid primordium neither at the placode stage (Fagman et al., 2004; Parlato et al., 2004; Moore-Scott and Manley, 2005) nor in the bud before it fuses event with the UB (HF and MN, unpublished results of genetic fate mapping using Shh-Cre/ROSA26R recombination). The effect is therefore most likely non-cell autonomous, i.e. the source of Shh and probably also the primary tissue target of Shh are located outside the primordium itself.

Homozygous inactivation of Shh in humans, as in mice, causes serious malformations in many organ systems and is not compatible with extra-uterine life. It is therefore perhaps not surprising that germ line Shh mutations have so far not been detected in patients with thyroid dysgenesis (Muzza et al., 2008). However, impaired function of factors implicated in some but not all actions of the Shh signaling pathway may give a milder phenotype. One example of this is the DiGeorge syndrome candidate gene Tbxl recently found to play a role in thyroid bilobation (Fagman et al., 2007). In $T b x 1$ knockout embryos the thyroid is severely hypoplastic and amounts to less than $25 \%$ of the normal gland at E18.5. Moreover, the localization of thyroid tissue is mostly unilateral reminiscent of hemiagenesis. Tbx1 is expressed in the adjacent mesoderm but not in the thyroid primordium (Fagman et al., 2007), suggestive of a non-cell-autonomous mode of action. That this is the case has recently been conclusively demonstrated by the finding that target deletion of $T b x 1$ specifically in the anterior mesoderm, using the $\operatorname{Mespl}^{\text {Cre }}$ driver, recapitulates the general Tbxl null thyroid phenotype (Lania et al., 2009).

Three dimensional reconstructions of Shh deficient E18.5 mouse embryos reveal that the carotid arteries develop asymmetrically and are located on one side of the midline, coinciding with the unilateral localization of the thyroid rudiment, in (Alt et al., 2006a). A two-step model of vascular effects on thyroid morphogenesis was proposed, in which the thyroid primordium first reaches a 
position close to the OFT and thereafter attains its final shape (Alt et al., 2006a). This interaction was also suggested to explain the co-incidental difference in thyroid and vessel anatomy among species. In support of this model, Hoxa3 mutants show both a thyroid bilobation defect (Manley and Capecchi, 1995) and premature degeneration of the third pharyngeal arch arteries before the time point when thyroid bilobation normally commences (Kameda et al., 2002). Also in the Tbxl mutant with a single-lobed thyroid development of the caudal pharyngeal arch arteries is profoundly disturbed (Lindsay et al., 2001). The vessel hypothesis may be questioned by the notion that most patients with thyroid dysgenesis do not display obvious abnormalities of cervical vessel anatomy. Also, no cardiovascular aberrations have been reported in the sporadic cases of asymptomatic thyroid hemiagenesis detected by ultrasound screening (Korpal-Szczyrska et al., 2008). However, observations in the Tbxl null mice suggest a possible explanation to this contradiction. In the mutant embryo the thyroid bud remains connected to the endoderm for much longer than normally so that the primordium fails to keep a close association with the aortic sac as it retracts caudally (Fagman et al., 2007). When the thyroglossal duct eventually regresses the contact with the aortic sac is not re-established and downward migration of the thyroid is retarded. Nevertheless, in late embryogenesis the thyroid remnant in Tbxl mutants is often associated with one of the carotid homologues in a seemingly stochastic fashion (Fagman et al., 2007). Importantly, as bilateral vessels similar to carotids are present, Tbx1 deficiency does not impair symmetric development of vessels in the neck. The Tbx1 knockout thus represents an attractive animal model of thyroid hemiagenesis likely caused by defective interactions between thyroid progenitors and embryonic vessels at a critical time-point preceding final development of the vasculature.

\section{Nkx2-1 and Pax8 gene dosage cell-autonomously affects thyroid bilobation}

Compelling evidence indicating that thyroid bilobation is also regulated by cell-autonomous mechanisms comes from studies in mice compound heterozygous for $N k x 2-1$ and Pax8 (Amendola et al., 2005). On a specific genetic background (C57B16) these animals, which are clearly 
hypothyroid, display a high prevalence of thyroid hemiagenesis. Interestingly, the phenotype is not present after transfer to a Sv129 background. This demonstrates that $\mathrm{CH}$ and thyroid dysgenesis in mice can be of multigenic origin and that the condition is associated with C57B16 specific modifier alleles recessive to those in the $\mathrm{Sv} 129$ strain. As $\mathrm{Nkx} 2-1$ and Pax 8 are coexpressed in the developing thyroid but not in surrounding embryonic tissues this is likely a cell-autonomous event, which further indicates that the $N k x 2-1$ and $\operatorname{Pax} 8$ gene dosage is important to thyroid bilobation. Downstream transcriptional targets that mediate this function and the nature of the modifier loci remain to be identified.

\section{ROLE OF NEURAL CREST IN THYROID MORPHOGENESIS}

Migrating streams of the cranial neural crest (NC) originally derived from the ectoderm contributes largely to craniofacial and pharyngeal development. A key role of the NC cells (NCC) is to invade and pattern the pharyngeal apparatus consisting of the pharyngeal arches and pouches, the latter of which give rise to the thymus, parathyroid and UB primordia. Experimental ablation of the NC leads to thyroid hypoplasia or hemiagenesis (Bockman and Kirby, 1984), indicating that also the median thyroid primordium is influenced in this process. Indeed, recent fate mapping of NCC and their progeny using the Wnt1-Cre driver has revealed that the developing thyroid is heavily invested by NC derived ectomesenchyme (Jiang et al., 2000). Also the mesenchyme of the mature gland is at least partly of NC origin as evident from chimeric quail and chick embryos (Le Lievre and Le Douarin, 1975) and Wnt1-Cre based fate mapping (Kameda et al., 2007a). Considering the profound impact defective NCC migration has on the gross pharyngeal anatomy it is likely that the thyroid phenotype is secondary to other morphogenetic events.

Ablation of the NC leads to defective formation of the aortopulmonary septum leading to persistent truncus arteriosus and transpositions of the great vessels (Kirby et al., 1983). Of particular interest, in NC ablated embryos the third pharyngeal arch arteries are hypoplastic (Bockman et al., 1987) and lose bilateral symmetry (Waldo et al., 1996), resembling the phenotype of Shh knockouts in 
which thyroid bilobation fails (Fagman et al., 2006; Alt et al., 2006a). In fact, the constellation of defects resulting from $\mathrm{NC}$ ablation is reminiscent of the DiGeorge syndrome, considered to be caused at least partly by insufficient colonization of the pharyngeal apparatus by NCC (Wurdak et al., 2006). A central player in this mechanism is the DiGeorge syndrome candidate gene Tbxl expressed in the pharyngeal endoderm and mesoderm but not in the NCC (Lindsay et al., 2001). Tbx1 signaling via downstream mediators such as FGF8 (Vitelli et al., 2002) is believed to promote survival and development of NCC (Macatee et al., 2003). This indicates a possibility that loss of pharyngeal NCC might contribute to the thyroid phenotype recognized in mouse mutants deficient of Tbx1 and FGF8 (Fagman et al., 2007; Lania et al., 2009). Indeed, thyroid hypoplasia caused by inactivation of Tbxl in the mesenchyme is rescued by overexpression of FGF8 from the Tbxl locus (Lania et al., 2009). Even though the primary target of FGF8 action has been suggested to be the foregut endoderm the possibility of disrupted interactions with NCC needs to be further investigated.

A role of NC in thyroid morphogenesis is supported by observations in murine models in which other genes implicated in NCC survival and migration are deleted. NCC populating the pharyngeal arches express the receptor $\left(\mathrm{ET}_{\mathrm{A}}\right)$ for endothelin-1 (ET1), and $\mathrm{ET}_{\mathrm{A}}$ deficient embryos display an array of defects in NC derivatives (Clouthier et al., 1998). Interestingly, in ET1 knockouts the thyroid gland is hypoplastic albeit bilobed (Kurihara et al., 1995). Of note, impaired ET1 signaling does not affect the third pharyngeal arch arteries, which initially develop normally in the $\mathrm{ET}_{\mathrm{A}}$ mutant (Yanagisawa et al., 1998). As the small thyroid in this mutant has a largely normal shape this suggests that NCC might be required for growth rather than bilobation. Thyroid hypoplasia accompanied by diminished NCC infiltration of the pharyngeal arches is also observed in mice deficient of Pax3 (radiation induced in the splotch mutant) (Franz, 1989), fibulin-1 (Cooley et al., 2008) and the natural BMP antagonist chordin (Bachiller et al., 2003). Whether the NC influences thyroid growth directly by local action of NCC infiltrating the embryonic thyroid stroma or 
indirectly through gross changes of pharyngeal patterning characterising the NCC ablated embryo need further studies to be elucidated.

\section{DEVELOPMENT OF LATERAL THYROID PRIMORDIA AND C-CELL PRECURSORS}

As mentioned, in higher vertebrates the paired UB give rise to the lateral thyroid primordia that fuse with the median thyroid anlage. The primary role of the fusion of primordia is generally assumed to be the transfer of C-cell precursors into the thyroid (Fig. 3C-E). Regardless the fact that we do not yet know the functional meaning of why calcitonin-producing C-cells attain an intrathyroidal position, the mechanisms regulating this process are important to elucidate, as it this may shed light on which embryonic factors are implicated in the proliferation and migration of C-cell precursors. This may in turn bring novel knowledge on the biology of medullary thyroid cancer originating from adult C-cells.

Etymologically, the term "ultimobranchial" refers to the site of origin of the UB, which is the most posterior (ultimate) of the pharyngeal (branchial) pouches. Hence, the UB develop from the fifth pharyngeal pouches in humans and from the fourth pouches in mice. In mouse embryos this is first evident as a bilateral outpocketings from the foregut endoderm at E10 (Fagman et al., 2006). The connection of the UB to the gut tube thereafter gets progressively slender and at E11.5 the UB completely dissociate from the pouch that becomes part of the prospective pharyngeal wall. The free UB move anteriorly before fusion with the midline thyroid primordium takes place at E13.5. The epithelial cells forming the UB have a high proliferation rate, but once contact with the midline primordium is established cell proliferation ceases (Fagman et al., 2006), possibly by inhibitory signaling from the follicular cell progenitors. Starting at the pouch stage the prospective UB epithelium gradually acquires $\mathrm{Nkx} 2-1$ expression ( $\mathrm{HF}$ and $\mathrm{MN}$, unpublished results). At E11.5 almost all cells of the free UB express Nkx2-1. However, the cell content of the mature UB is not uniform; a small number of Nkx2-1 negative UB cells express the basal/stem cell marker p63 (Kusakabe et al., 2006). 


\section{Factors regulating the formation of ultimobranchial bodies}

In Nkx2-1 null embryos the initial development of the UB is not affected but at E13.5 both UB are hypoplastic and contain numerous apoptotic cells (Kusakabe et al., 2006). This is similar to the median thyroid primordium indicating that $\mathrm{Nkx} 2-1$ is not involved in the specification of UB progenitor cells but necessary for their subsequent survival. The Nkx2-1 deficient UB rudiments persist in late development and form cystic structures largely populated by p63 positive cells. These cysts are negative for TG and calcitonin and bear resemblance to the "second kind" of thyroid follicle that has been recognized for long (Wetzel and Wollman, 1969; Kusakabe et al., 2006). Interestingly, in $N k x 2-1$ heterozygous embryos the UB fail to fuse completely with the midline primordium and the C-cells disperse abnormally (Kusakabe et al., 2006). This suggests that both UB and thyroid progenitors depend on the $N k x 2-1$ gene dosage for their interaction during fusion. In line with this, in zebrafish the ultimobranchial glands remain separated from the thyroid gland and do not express the $N k x 2-1$ orthologs $n k 2-1 a$ or $n k 2-1 b$ (Alt et al., 2006b). Speculatively, $N k x 2-1$ has adopted a role in UB development late from an evolutionary point of view related to the presumed need of fusion between the median and lateral thyroid primordia in higher vertebrates.

Hoxa3, belonging to a paralog group of anteroposterior polarity regulators in the embryo, is expressed in the third and fourth pharyngeal pouches (Manley and Capecchi, 1995). In Hoxa3 mutants the UB fail to fuse with the median thyroid, which also show signs of defective bilobation. This phenotype is further pronounced when additional Hox paralogs are deleted (Manley and Capecchi, 1998). It has been suggested that the transcriptional activator Eya1 functions downstream of Hoxa3 in the pharyngeal pouches and the UB persist as cystic structures containing C-cells in Eyal deficient embryos (Xu et al., 2002). A role of FGF-signaling for the survival and migration of UB is suggested by results from FRS $2 \alpha$ mutants where UB are often absent or retained in the pharyngeal endoderm (Kameda et al., 2009)., Finally, the UB are absent in mice deficient of Pax9 (Peters et al., 1998) and Tbx1 (Fagman et al., 2007). This is likely because overall morphogenesis 
of the caudal parts of the pharyngeal apparatus is abrogated when these transcription factors are lacking.

\section{The C-cell origin - neural crest or endoderm?}

With the advent of fluorescent amine tracing it became evident that the parafollicular C-cells in higher vertebrates derive from the UB (Pearse and Carvalheira, 1967). This notion has later gained further support by the finding that differentiated C-cells are restricted to the UB in animal models where these have not fused with the midline thyroid primordium (Manley and Capecchi, 1995; Mansouri et al., 1998; Xu et al., 2002). However, studies tracing the C-cell progenitors at earlier stages of development have largely been lacking due to a paucity of specific markers of the precursor cells. In fact, calcitonin is expressed first when C-cells are present in the thyroid and become terminally differentiated. The prevailing concept of a $\mathrm{NC}$ origin of $\mathrm{C}$-cells therefore rests on other lines of evidence, one is more conceptual and derived by assuming a common developmental origin of all neuroendocrine cells, the other is based on data obtained from xenotransplants of embryonic tissues. As the embryonic source of C-cells at least in higher vertebrates has recently been challenged (Kameda et al., 2007a), it is relevant to highlight some of the historic background.

When cells of the APUD-series were identified by functional criteria of Amine Precursor Uptake and Decarboxylation, the C-cells were soon found to be included in the family (Pearse, 1969). This lineage also comprised cells of the adrenal medulla, enterochromaffin cells of the intestines, lungs and pancreatic islets. Given their shared endocrine and neural properties, a common embryological origin was envisioned and suggested to be the NC (Pearse, 1969). By formaldehyde induced fluorescence studies it was concluded that NCC invade the developing endoderm and pancreas, supposedly giving rise to APUD cells at these locations (Pearse and Polak, 1971). To experimentally prove this hypothesis the classical quail-chick chimera method proved valuable to trace NCC in avian species and was employed by LeDourain and co-workers (Teillet et al., 2008). 
By this approach, quail NCC transplanted to chick embryos and identified by their characteristic chromatin structure by light microscopy were demonstrated to invade the chick ultimobranchial gland and differentiate into C-cells based in calcitonin immunostaining (Polak et al., 1974). Without formal proof, this notion has then been generally accepted to be valid also for higher vertebrates as mice and humans.

Today, the general view is that the neuroendocrine cells in the intestine and pancreas do not stem from the NC but are truly endodermal from the start of embryogenesis (reviewed in (Delcore and Friesen, 1993; Andrew et al., 1998). This opens up the possibility that also other cells of the former APUD lineage might descend from the endoderm. Even though a NC origin of calcitonin-producing cells in the chick ultimobranchial glands is convincingly shown (Polak et al., 1974), it is not immediately evident that this finding can be extrapolated to higher mammals. Later studies in chicken have revealed that cells with neuronal characteristics derived from the distal vagal ganglion invade the ultimobranchial gland and give rise to C-cells (Kameda, 1995). Since both parasympathetic and sensory ganglia are NC derivatives this supports a NC origin of avian C-cells. In contrast, during development the mouse UB is not in the immediate vicinity of ganglia or nerve bundles and there is no evidence of such a contribution to thyroid C-cells (Kameda et al., 2007a). Even though this does not exclude that these are of NC origin, it clearly suggests that avian C-cells arise by mechanisms distinct from C-cells in mouse and humans. The most compelling evidence favouring the hypothesis that C-cells of the mouse thyroid are likely not of NC origin comes from a recent lineage tracing experiment, using the Wnt1-Cre driver that faithfully marks the migrating NC population and its descendants (Jiang et al., 2000). It was demonstrated that Wnt1-expressing NCC cells did not show up in the UB at any developmental stage, nor was the distribution pattern overlapping with the calcitonin-positive cells in the mature gland (Kameda et al., 2007a). The endoderm of the fourth pharyngeal pouch therefore is the most obvious candidate origin of C-cell precursors in the mouse. This possibility needs to be formally proven, ultimately by genetic fate mapping of endoderm progenitors. However, in support of this novel concept Isl, which marks 
definitive endoderm but not NCC was recently found to be expressed first in the UB epithelium and later on only by C-cell precursors and C-cells (Westerlund et al., 2008). Notably, the signaling pathways that could impose neuroendocrine features on cells of supposedly endodermal derivation are beginning to be characterized. The identification of the transcription factor Mash1 (Kameda et al., 2007b) and Is11 (Westerlund et al., 2008) as potential regulators of C-cell development signifies initial steps in this direction.

\section{CONCLUDING REMARKS AND FUTURE DIRECTIONS}

The morphological aspects of thyroid development are now well characterized in experimental animal models, i.e. mouse and zebrafish, mainly used for investigation of mechanisms. There is also available a great number of genetic models in which different types of thyroid malformations are reported (Table 1), the phenotypes of which have been discussed in this overview. With this combined knowledge, it is envisaged that adoption of novel gene targeting strategies will make it possible to further elucidate how the different stages of thyroid morphogenesis are induced and executed at the molecular level. Eventually, this will provide a better understanding of the development of thyroid dysgenesis in man.

So far most efforts have been focused on cell-autonomous transcription factors. However, it has become evident that these developmental regulators are important after thyroid specification is already induced. Insights into to signals that govern induction of a thyroid fate, which may explain athyreosis if missing, are largely lacking. Identification of the factor(s) controlling the concerted expression of Nkx2-1, Pax8, Foxe1 and Hhex in thyroid progenitor cells is therefore an important area for further studies. It is conceivable that disturbed specification might be due to a variety of aberrations that affect the level of an inductive signal or the juxtaposition of the endoderm to a signaling centre rather than to mutations of a yet unidentified thyroid specific master gene. Also the signals that make a subset of endodermal cells competent to respond to signaling towards a thyroid fate need to be characterized. A putative morphogenetic role of modifier loci implicated in the 
variable phenotype observed in double heterozygous knockouts of Nkx2-1 and Pax8 with different genetic background may shed light on the postulated polygenic origin of thyroid dysgenesis. Given the largely sporadic occurrence of thyroid dysgenesis the investigation of epigenetic alterations and other mechanisms such as copy number variations are certainly warranted in this context.

Recently, the contribution of non cell-autonomous factors in thyroid morphogenesis has attracted attention. Studies in zebrafish have provided initial evidence for the crucial importance of hand2/FGF signaling in early stages of thyroid development and a possible influence of cardiogenic mesoderm on thyroid induction, a notion that has been corroborated and further elaborated in mouse models. However, morphogenetic signals generated outside the thyroid primordium, like those regulated by the Shh-Tbx1 pathway and likely also other factors impacting on pharyngeal patterning, are evidently important to determine the size and final position of the thyroid gland. Further understanding how the thyroid reaches its ultimate position far away from the region of specification requires a more detailed picture on how thyroid precursors move as a coherent cluster and the possible role of adjacent embryonic structures in the process. This will likely provide further clues to the pathogenesis of thyroid ectopia as well as general insights into how groups of endodermal cells move. Taken together, the combined use of the various animal model systems described here with their specific advantages will be essential in these further efforts. 


\section{ACKNOWLEDGEMENTS}

Mats Grände, Jessica Westerlund and Louise Andersson are acknowledged for valuable input. The authors want to thank Roberto di Lauro, Mario de Felice, Geppino Falco, Elena Amendola and other members of the Nilsson, di Lauro and de Felice labs for fruitful discussions. Paolo Sordino and Immacolata Porreca are acknowledged for providing photos of zebrafish. HF is supported by the Göteborg Medical Society and an EMBO long term fellowship. MN is funded by project grants from the Swedish Research Council and the Swedish Cancer Society. 
Table 1. Animal models of thyroid dysgenesis.

Mutant $^{1}$ Features

Thyroid phenotype

Additional phenotypes

Reference $^{2}$

\section{Zebrafish}

ace

bon

cas

$c y c$

fau

hand2

hhex

$n k 2.1 a$

noi (pax2.1)

оер

Nodal cofactor

Mouse (mus musculus)

Chordin extracellular BMP antagonist

Edn1 endothelin-1; signaling peptide

Eyal hypoplasia

athyreosis

athyreosis

hypoplasia

athyreosis

athyreosis or hypoplasia

ar

athyreosis or hypoplasia

athyreosis

athyreosis

athyreosis lack of mid-hindbrain-boundary lack of cerebellum

overall reduction of endoderm

absence of endoderm

overall reduction of endoderm neural tube defects, cyclopia

aplasia of liver, pancreas, thymus

heart, pharynx, pectoral fin defects

liver aplasia

forebrain defect

lack of mid-hindbrain-boundary and pronephric duct

absence of endoderm

cardiac outflow tract defects,

craniofacial, cardiac and thymus defects

aplasia of kidneys, thymus, parathyroid aplasia of thymus, parathyroid
(Wendl et al., 2007)

(Elsalini and Rohr, 2003)

(Elsalini et al., 2003)

(Elsalini et al., 2003)

(Reiter et al., 2001)

(Wendl et al., 2007)

(Elsalini et al., 2003)

(Elsalini et al., 2003)

(Wendl et al., 2002)

(Elsalini et al., 2003) hypoplasia, absent isthmus

hypoplasia ultimobranchial body defects
(Bachiller et al., 2003)

(Kurihara et al., 1995)

(Xu et al., 2002) 


\begin{tabular}{|c|c|c|c|}
\hline Fgflo & growth factor & athyreosis & $\begin{array}{l}\text { aplasia of limbs, lungs, } \\
\text { pituitary, salivary glands }\end{array}$ \\
\hline Fibulin-1 & ECM protein & hypoplasia & craniofacial, cardiac and thymus de \\
\hline Foxel & forkhead transcription factor & ectopia or athyreosis & cleft palate \\
\hline$F R S 2 \alpha$ & transducer of FGF signaling & $\begin{array}{l}\text { bilobation defect, hypoplasia } \\
\text { ultimobranchial body defects }\end{array}$ & thymus and parathyroid defects \\
\hline Hhex & homeobox transcription factor & athyreosis & forebrain truncations, liver aplasia \\
\hline $\begin{array}{l}\text { Hoxa3 } \\
\text { Hoxb3 } \\
\text { Hoxd3 }\end{array}$ & homeobox transcription factors & $\begin{array}{l}\text { bilobation defect, hypoplasia } \\
\text { ultimobranchial body defects }\end{array}$ & $\begin{array}{l}\text { cardiovascular and skeletal defects } \\
\text { thymus and parathyroid aplasia }\end{array}$ \\
\hline Isll & $\begin{array}{l}\text { LIM homeodomain } \\
\text { transcription factor }\end{array}$ & hypoplasia of thyroid placode & heart, pancreas and neural defects \\
\hline$N k \times 2-1$ & $\begin{array}{l}\text { homeodomain transcription } \\
\text { factor }\end{array}$ & athyreosis & pulmonary aplasia, neural defects \\
\hline$N k \times 2-5$ & $\begin{array}{l}\text { homeodomain transcription } \\
\text { factor }\end{array}$ & hypoplasia of thyroid placode & cardiac defects \\
\hline Pax3 & paired-box transcription factor & $\begin{array}{l}\text { bilobation defect, hypoplasia } \\
\text { ultimobranchial body defects }\end{array}$ & $\begin{array}{l}\text { cardiac outflow tract defects } \\
\text { thymus and parathyroid defects }\end{array}$ \\
\hline $\operatorname{Pax} 8$ & paired-box transcription factor & athyreosis & reproductive tract defects \\
\hline Shh & secreted morphogen & bilobation defect & $\begin{array}{l}\text { holoprosencephaly, cardiac } \\
\text { and outflow tract defects }\end{array}$ \\
\hline Tbxl & T-box transcription factor & $\begin{array}{l}\text { bilobation defect, hypoplasia } \\
\text { C-cell aplasia }\end{array}$ & $\begin{array}{l}\text { cardiac outflow tract defects, } \\
\text { aplasia of thymus, parathyroid }\end{array}$ \\
\hline twisted & $\begin{array}{l}\text { extracellular modulator of } \\
\text { BMP signaling }\end{array}$ & loss of Hhex at bud stage & $\begin{array}{l}\text { vertebral defects, spectrum of } \\
\text { midline defects, agnathia }\end{array}$ \\
\hline
\end{tabular}


Table 2. Timing of key morphogenetic events during thyroid development in different species. E, embryonic day; hpf, hours post fertilization.

\begin{tabular}{lcccc} 
& Specification & Budding & Migration & Follicle formation \\
\hline Human $^{1}$ & E20-E22 & E24 & E25-E50 & E70 \\
Mouse $^{2}$ & E8.5 & E10 & E10.5-E13.5 & E15.5 \\
Zebrafish $^{3}$ & $24 \mathrm{hpf}$ & $32 \mathrm{hpf}$ & $35-45 \mathrm{hpf}$ & $55 \mathrm{hpf}$
\end{tabular}

1 (De Felice and Di Lauro, 2004)

2 (Fagman et al., 2006)

3 (Alt et al., 2006b) 


\section{FIGURE LEGENDS}

Figure 1. Early thyroid morphogenesis in the mouse embryo; formation of the gut tube. A. Thyroid placode identified by Nkx2-1 expression in the ventral foregut of an E9.5 mouse embryo. The distribution of cell nuclei indicates that the primordium is pseudostratified. Initial bud formation is starting in the posterior part of the placode, closely associated to the aortic sac (dotted line). Sagittal section. as, aortic sac; pl, pharyngeal lumen; tp, thyroid placode. B. After gastrulation, the endoderm (blue) covers the outside of the embryo. The extraembryonic region has been removed and the inner parts containing ectoderm and mesoderm are indicated (light blue). By ventral folding (arrow) of the endoderm the anterior region (yellow *) will later eventually become the floor of the foregut whereas at this stage posteriorly located endoderm (green *) will later form the roof of the prospective gut tube. C. Ventral view of an embryo slightly more advanced than in (A). By folding of an endodermal lip (surrounded by black line) the anterior intestinal pocket starts to form. The arrow indicates the entrance to this by the anterior intestinal portal (AIP). The presumptive endoderm region from which thyroid precursors might originate is indicated (red, dotted circle). D. Sagittal view of the cranial region of an embryo modeling the gut tube (blue) when folding of the endoderm gut is nearly completed. Arrow indicates the AIP that opens into the intestinal pocket. Endoderm regions are indicated $(*)$ for comparison with their respective positions before folding (see A). Heart mesenchyme (red) is closely apposed to the definitive ventral endoderm.

Adapted from (Wells and Melton, 1999; Tremblay and Zaret, 2005).

Figure 2. Overview of key steps of embryonic development and thyroid morphogenesis in zebrafish. A. 1-cell stage, zygote period. Cytoplasm has accumulated and the blastodisc (bd) is distinct from the yolk sac (ys). B. 16-cell stage, cleavage period. By subsequent cleavages of the blastodisc, blastomeres are generated at the animal pole (ap) opposite to the vegetal pole (vp) of the yolk sac. C. 50\%-epiboly, transition between blastula and gastrula periods. During epiboly the blastoderm progressively spreads towards the vegetal pole, like a cap being pulled over the head. 
Percentage indicates how much of the distance between the poles that is covered. A local accumulation of cells at $(*)$ will form the embryonic shield that distinguishes the dorsal side (d) from the ventral (v) of the embryo. Gastrulation occurs by involution of cells at the blastoderm margin. Ectoderm derives from a region close to the animal pole, mesoderm from a broad intermediate area and endoderm from the equatorial zone. As demonstrated by fate-mapping the thyroid originates from dorsal blastomeres in the area encircled by a red dotted line. D. 6-somite stage, segmentation period. The definitive anatomy of the embryo can be discerned and the optic primordium is evident. The approximate region where the thyroid primordium will be located is indicated by red dotted line. E. Whole mount in situ hybridization of nk2.1a at 24 hours post fertilization (hpf). The endoderm constitutes a thin layer of cells on the dorsal surface of the yolk sac (blue dotted line). The thyroid primordium is indicated by arrow. Rostral nk2.1a expression is in neural progenitors of the developing brain. F. Adult zebrafish (anterior part) in which the thyroid follicles (green) being loosely dispersed along the ventral aorta (red) are depicted. G. Ventral view of zebrafish with whole mount immunostaining of thyroxin indicating accumulation of $\mathrm{T}_{4}$ in the thyroid follicles (arrow) at $120 \mathrm{hpf}$. Red dotted line indicates the approximate position of the heart (h) and the ventral aorta, black dotted lines outline the ceratohyal cartilages (ch).

Adapted from (Kimmel et al., 1995).

Figure 3. Dissociation of the mouse thyroid bud from the endoderm and formation of a bilobed gland. A. The thyroid bud (evidenced by red Nkx2-1 staining) at E10.5 of mouse development. The primordium is still broadly connected to the foregut endoderm. The bud maintains association with the aortic sac (dotted line) that has started to retract caudally. Sagittal section. as, aortic sac; pl, pharyngeal lumen. B. After dissociation from the endoderm (blue) the thyroid bud transiently looses contact with the caudally retracting aorta. The point of bud outgrowth can be seen as a slight depression of the endoderm that later persists as the foramen caecum $(*)$. After a transient phase of supposedly active migration (indicated by arrow), the primordium (green) comes to rest as a cap- 
like structure on the cranial surface of the aortic sac (red) at E11.5. C. In a schematic, frontal view the thyroid primordium (green) extends bilaterally along the course of the $3^{\text {rd }}$ pharyngeal arch arteries. The lateral ends of the thyroid and the ultimobranchial bodies (brown) are approaching each other (arrow). Dotter arrow indicates the plane of section in (B). Ao, aorta; D, dorsal aorta; 3, $3^{\text {rd }}$ pharyngeal arch arteries; $4,4^{\text {th }}$ pharyngeal arch arteries. D. At E13.5 the ultimobranchial bodies have made contact and started to merge (arrow) with the lateral ends of the thyroid primordium. The pharyngeal arch arteries and dorsal aortae remodel into the carotid arteries and the final vascular anatomy as well as the bilobed shape of the thyroid can be discerned. E. At E18.5 the final shape of the thyroid is established with bilateral lobes close to the carotid arteries. A thin, pretracheal isthmus connects the caudal poles. C-cells and remnants of the ultimobranchial bodies (brown) are concentrated to the central regions of the lobes.

Adapted from (Alt et al., 2006a). 


\section{REFERENCES}

Abe, M., Tamamura, Y., Yamagishi, H., Maeda, T., Kato, J., Tabata, M. J., Srivastava, D., Wakisaka, S., et al., 2002. Tooth-type specific expression of dHAND/Hand2: possible involvement in murine lower incisor morphogenesis. Cell Tissue Res 310, 201-212.

Al Taji, E., Biebermann, H., Limanova, Z., Hnikova, O., Zikmund, J., Dame, C., Gruters, A., Lebl, J., et al., 2007. Screening for mutations in transcription factors in a Czech cohort of 170 patients with congenital and early-onset hypothyroidism: identification of a novel PAX8 mutation in dominantly inherited early-onset non-autoimmune hypothyroidism. Eur J Endocrinol 156, 521-529.

Alt, B., Elsalini, O. A., Schrumpf, P., Haufs, N., Lawson, N. D., Schwabe, G. C., Mundlos, S., Gruters, A., et al., 2006a. Arteries define the position of the thyroid gland during its developmental relocalisation. Development 133, 3797-3804.

Alt, B., Reibe, S., Feitosa, N. M., Elsalini, O. A., Wendl, T., Rohr, K. B., 2006b. Analysis of origin and growth of the thyroid gland in zebrafish. Dev Dyn 235, 1872-1883.

Amendola, E., De Luca, P., Macchia, P. E., Terracciano, D., Rosica, A., Chiappetta, G., Kimura, S., Mansouri, A., et al., 2005. A mouse model demonstrates a multigenic origin of congenital hypothyroidism. Endocrinology 146, 5038-5047.

Andrew, A., Kramer, B., Rawdon, B. B., 1998. The origin of gut and pancreatic neuroendocrine (APUD) cells--the last word? J Pathol 186, 117-118.

Aoki, T. O., David, N. B., Minchiotti, G., Saint-Etienne, L., Dickmeis, T., Persico, G. M., Strahle, U., Mourrain, P., et al., 2002. Molecular integration of casanova in the Nodal signalling pathway controlling endoderm formation. Development 129, 275-286.

Apelqvist, A., Ahlgren, U., Edlund, H., 1997. Sonic hedgehog directs specialised mesoderm differentiation in the intestine and pancreas. Curr Biol 7, 801-804.

Arnold, M. B., Arulanantham, K., Bapat, V., Bennett, A., Bigos, S. T., Bode, H. H., Brown, R., Crawford, J. D., et al., 1981. Effects of neonatal screening for hypothyroidism: prevention of mental retardation by treatment before clinical manifestations. New England congenital hypothyroidism collaborative. Lancet 2, 1095-1098.

Bachiller, D., Klingensmith, J., Shneyder, N., Tran, U., Anderson, R., Rossant, J., De Robertis, E. M., 2003. The role of chordin/Bmp signals in mammalian pharyngeal development and DiGeorge syndrome. Development 130, 3567-3578.

Baum, B., Settleman, J., Quinlan, M. P., 2008. Transitions between epithelial and mesenchymal states in development and disease. Semin Cell Dev Biol 19, 294-308.

Bianco, A., Poukkula, M., Cliffe, A., Mathieu, J., Luque, C. M., Fulga, T. A., Rorth, P., 2007. Two distinct modes of guidance signalling during collective migration of border cells. Nature 448, 362-365.

Biben, C., Wang, C. C., Harvey, R. P., 2002. NK-2 class homeobox genes and pharyngeal/oral patterning: Nkx2-3 is required for salivary gland and tooth morphogenesis. Int J Dev Biol 46, 415-422.

Blixt, A., Mahlapuu, M., Aitola, M., Pelto-Huikko, M., Enerback, S., Carlsson, P., 2000. A forkhead gene, FoxE3, is essential for lens epithelial proliferation and closure of the lens vesicle. Genes Dev 14, 245-254.

Bockman, D. E., Kirby, M. L., 1984. Dependence of thymus development on derivatives of the neural crest. Science 223, 498-500.

Bockman, D. E., Redmond, M. E., Waldo, K., Davis, H., Kirby, M. L., 1987. Effect of neural crest ablation on development of the heart and arch arteries in the chick. Am J Anat 180, 332-341.

Bohinski, R. J., Di Lauro, R., Whitsett, J. A., 1994. The lung-specific surfactant protein B gene promoter is a target for thyroid transcription factor 1 and hepatocyte nuclear factor 3 , indicating common factors for organ-specific gene expression along the foregut axis. Mol Cell Biol 14, 5671-5681. 
Bort, R., Signore, M., Tremblay, K., Martinez Barbera, J. P., Zaret, K. S., 2006. Hex homeobox gene controls the transition of the endoderm to a pseudostratified, cell emergent epithelium for liver bud development. Dev Biol 290, 44-56.

Bubuteishvili, L., Garel, C., Czernichow, P., Leger, J., 2003. Thyroid abnormalities by ultrasonography in neonates with congenital hypothyroidism. J Pediatr 143, 759-764.

Cai, C. L., Liang, X., Shi, Y., Chu, P. H., Pfaff, S. L., Chen, J., Evans, S., 2003. Isl1 identifies a cardiac progenitor population that proliferates prior to differentiation and contributes a majority of cells to the heart. Dev Cell 5, 877-889.

Capen, C. C., Comparative anatomy and physiology. In: Braverman, L. E., R. D. Utiger, Eds.), Werner \& Ingbar's The Thyroid: a fundamental and clinical text. Lipincott, Williams \& Williams, Philadelphia, 2000, pp. 20-44.

Casanova, J. B., Daly, R. C., Edwards, B. S., Tazelaar, H. D., Thompson, G. B., 2000. Intracardiac ectopic thyroid. Ann Thorac Surg 70, 1694-1696.

Castanet, M., Leenhardt, L., Leger, J., Simon-Carre, A., Lyonnet, S., Pelet, A., Czernichow, P., Polak, M., 2005. Thyroid hemiagenesis is a rare variant of thyroid dysgenesis with a familial component but without Pax 8 mutations in a cohort of 22 cases. Pediatr Res 57, 908-913.

Castanet, M., Polak, M., Bonaiti-Pellie, C., Lyonnet, S., Czernichow, P., Leger, J., 2001. Nineteen years of national screening for congenital hypothyroidism: familial cases with thyroid dysgenesis suggest the involvement of genetic factors. J Clin Endocrinol Metab 86, 20092014.

Castanet, M., Polak, M., Leger, J., 2007. Familial forms of thyroid dysgenesis. Endocr Dev 10, 1528.

Celli, G., LaRochelle, W. J., Mackem, S., Sharp, R., Merlino, G., 1998. Soluble dominant-negative receptor uncovers essential roles for fibroblast growth factors in multi-organ induction and patterning. EMBO J 17, 1642-1655.

Clark, N. B., 1971. The ultimobranchial body of reptiles. J Exp Zool 178, 115-124.

Clark, O. H., Lambert, W. R., Cavalieri, R. R., Rapoport, B., Hammond, M. E., Ingbar, S. H., 1976. Compensatory thyroid hypertrophy after hemithyroidectomy in rats. Endocrinology 99, 988995.

Clifton-Bligh, R. J., Wentworth, J. M., Heinz, P., Crisp, M. S., John, R., Lazarus, J. H., Ludgate, M., Chatterjee, V. K., 1998. Mutation of the gene encoding human TTF-2 associated with thyroid agenesis, cleft palate and choanal atresia. Nat Genet 19, 399-401.

Clouthier, D. E., Hosoda, K., Richardson, J. A., Williams, S. C., Yanagisawa, H., Kuwaki, T., Kumada, M., Hammer, R. E., et al., 1998. Cranial and cardiac neural crest defects in endothelin-A receptor-deficient mice. Development 125, 813-824.

Cooley, M. A., Kern, C. B., Fresco, V. M., Wessels, A., Thompson, R. P., McQuinn, T. C., Twal, W. O., Mjaatvedt, C. H., et al., 2008. Fibulin-1 is required for morphogenesis of neural crest-derived structures. Dev Biol 319, 336-345.

D'Andrea, B., Iacone, R., Di Palma, T., Nitsch, R., Baratta, M. G., Nitsch, L., Di Lauro, R., Zannini, M., 2006. Functional inactivation of the transcription factor Pax 8 through oligomerization chain reaction. Mol Endocrinol 20, 1810-1824.

De Felice, M., Di Lauro, R., 2004. Thyroid development and its disorders: genetics and molecular mechanisms. Endocr Rev 25, 722-746.

De Felice, M., Di Lauro, R., 2007. Murine models for the study of thyroid gland development. Endocr Dev 10, 1-14.

De Felice, M., Ovitt, C., Biffali, E., Rodriguez-Mallon, A., Arra, C., Anastassiadis, K., Macchia, P. E., Mattei, M. G., et al., 1998. A mouse model for hereditary thyroid dysgenesis and cleft palate. Nat Genet 19, 395-398.

Deladoey, J., Vassart, G., Van Vliet, G., 2007. Possible non-Mendelian mechanisms of thyroid dysgenesis. Endocr Dev 10, 29-42. 
Delcore, R., Friesen, S. R., 1993. Embryologic concepts in the APUD system. Semin Surg Oncol 9, 349-361.

Dentice, M., Cordeddu, V., Rosica, A., Ferrara, A. M., Santarpia, L., Salvatore, D., Chiovato, L., Perri, A., et al., 2006. Missense mutation in the transcription factor NKX2-5: a novel molecular event in the pathogenesis of thyroid dysgenesis. J Clin Endocrinol Metab 91, 1428-1433.

Desai, T. J., Malpel, S., Flentke, G. R., Smith, S. M., Cardoso, W. V., 2004. Retinoic acid selectively regulates Fgf10 expression and maintains cell identity in the prospective lung field of the developing foregut. Dev Biol 273, 402-415.

Dessimoz, J., Opoka, R., Kordich, J. J., Grapin-Botton, A., Wells, J. M., 2006. FGF signaling is necessary for establishing gut tube domains along the anterior-posterior axis in vivo. Mech Dev 123, 42-55.

Deutsch, G., Jung, J., Zheng, M., Lora, J., Zaret, K. S., 2001. A bipotential precursor population for pancreas and liver within the embryonic endoderm. Development 128, 871-881.

Devos, H., Rodd, C., Gagne, N., Laframboise, R., Van Vliet, G., 1999. A search for the possible molecular mechanisms of thyroid dysgenesis: sex ratios and associated malformations. $\mathrm{J}$ Clin Endocrinol Metab 84, 2502-2506.

Di Palma, T., Nitsch, R., Mascia, A., Nitsch, L., Di Lauro, R., Zannini, M., 2003. The paired domain-containing factor Pax 8 and the homeodomain-containing factor TTF-1 directly interact and synergistically activate transcription. J Biol Chem 278, 3395-3402.

Douarin, N. M., 1975. An experimental analysis of liver development. Med Biol 53, 427-455.

Edsbagge, J., Johansson, J. K., Esni, F., Luo, Y., Radice, G. L., Semb, H., 2005. Vascular function and sphingosine-1-phosphate regulate development of the dorsal pancreatic mesenchyme. Development 132, 1085-1092.

El-Hodiri, H. M., Seufert, D. W., Nekkalapudi, S., Prescott, N. L., Kelly, L. E., Jamrich, M., 2005. Xenopus laevis FoxE1 is primarily expressed in the developing pituitary and thyroid. Int $\mathbf{J}$ Dev Biol 49, 881-884.

Elsalini, O. A., Rohr, K. B., 2003. Phenylthiourea disrupts thyroid function in developing zebrafish. Dev Genes Evol 212, 593-598.

Elsalini, O. A., von Gartzen, J., Cramer, M., Rohr, K. B., 2003. Zebrafish hhex, nk2.1a, and pax2.1 regulate thyroid growth and differentiation downstream of Nodal-dependent transcription factors. Dev Biol 263, 67-80.

Eyuboglu, E., Kapan, M., Ipek, T., Ersan, Y., Oz, F., 1999. Ectopic thyroid in the abdomen: report of a case. Surg Today 29, 472-474.

Fagman, H., Andersson, L., Nilsson, M., 2006. The developing mouse thyroid: embryonic vessel contacts and parenchymal growth pattern during specification, budding, migration, and lobulation. Dev Dyn 235, 444-455.

Fagman, H., Grande, M., Edsbagge, J., Semb, H., Nilsson, M., 2003. Expression of classical cadherins in thyroid development: maintenance of an epithelial phenotype throughout organogenesis. Endocrinology 144, 3618-3624.

Fagman, H., Grande, M., Gritli-Linde, A., Nilsson, M., 2004. Genetic deletion of sonic hedgehog causes hemiagenesis and ectopic development of the thyroid in mouse. Am J Pathol 164, $1865-1872$.

Fagman, H., Liao, J., Westerlund, J., Andersson, L., Morrow, B. E., Nilsson, M., 2007. The 22q11 deletion syndrome candidate gene Tbx 1 determines thyroid size and positioning. Hum Mol Genet 16, 276-285.

Franklin, V., Khoo, P. L., Bildsoe, H., Wong, N., Lewis, S., Tam, P. P., 2008. Regionalisation of the endoderm progenitors and morphogenesis of the gut portals of the mouse embryo. Mech Dev 125, 587-600.

Franz, T., 1989. Persistent truncus arteriosus in the Splotch mutant mouse. Anat Embryol (Berl) 180, 457-464. 
Friedl, P., Gilmour, D., 2009. Collective cell migration in morphogenesis, regeneration and cancer. Nat Rev Mol Cell Biol 10, 445-457.

Friedrichsen, S., Christ, S., Heuer, H., Schafer, M. K., Mansouri, A., Bauer, K., Visser, T. J., 2003. Regulation of iodothyronine deiodinases in the Pax8-/- mouse model of congenital hypothyroidism. Endocrinology 144, 777-784.

Friedrichsen, S., Christ, S., Heuer, H., Schafer, M. K., Parlow, A. F., Visser, T. J., Bauer, K., 2004. Expression of pituitary hormones in the Pax8-/- mouse model of congenital hypothyroidism. Endocrinology 145, 1276-1283.

Gasser, R. F., 2006. Evidence that some events of mammalian embryogenesis can result from differential growth, making migration unnecessary. Anat Rec B New Anat 289, 53-63.

Goldin, G. V., Hindman, H. M., Wessells, N. K., 1984. The role of cell proliferation and cellular shape change in branching morphogenesis of the embryonic mouse lung: analysis using aphidicolin and cytochalasins. J Exp Zool 232, 287-296.

Gotz, M., Huttner, W. B., 2005. The cell biology of neurogenesis. Nat Rev Mol Cell Biol 6, $777-$ 788.

Gritli-Linde, A., Lewis, P., McMahon, A. P., Linde, A., 2001. The whereabouts of a morphogen: direct evidence for short- and graded long-range activity of hedgehog signaling peptides. Dev Biol 236, 364-386.

Gualdi, R., Bossard, P., Zheng, M., Hamada, Y., Coleman, J. R., Zaret, K. S., 1996. Hepatic specification of the gut endoderm in vitro: cell signaling and transcriptional control. Genes Dev 10, 1670-1682.

Gungor, B., Kebat, T., Ozaslan, C., Akilli, S., 2002. Intra-abdominal ectopic thyroid presenting with hyperthyroidism: report of a case. Surg Today 32, 148-150.

Hebrok, M., Kim, S. K., Melton, D. A., 1998. Notochord repression of endodermal Sonic hedgehog permits pancreas development. Genes Dev 12, 1705-1713.

Hilfer, S. R., Brown, J. W., 1984. The development of pharyngeal endocrine organs in mouse and chick embryos. Scan Electron Microsc 2009-2022.

Hilfer, S. R., Marrero, L., Sheffield, J. B., 1990. Patterns of cell movement in early organ primordia of the chick embryo. Anat Rec 227, 508-517.

Hilfer, S. R., Palmatier, B. Y., Fithian, E. M., 1977. Precocious evagination of the embryonic chick thyroid in ATP-containing medium. J Embryol Exp Morph 42, 163-175.

Hiruta, J., Mazet, F., Yasui, K., Zhang, P., Ogasawara, M., 2005. Comparative expression analysis of transcription factor genes in the endostyle of invertebrate chordates. Dev Dyn 233, 10311037.

Jiang, X., Rowitch, D. H., Soriano, P., McMahon, A. P., Sucov, H. M., 2000. Fate of the mammalian cardiac neural crest. Development 127, 1607-1616.

Jung, J., Zheng, M., Goldfarb, M., Zaret, K. S., 1999. Initiation of mammalian liver development from endoderm by fibroblast growth factors. Science 284, 1998-2003.

Kameda, Y., 1995. Evidence to support the distal vagal ganglion as the origin of C cells of the ultimobranchial gland in the chick. J Comp Neurol 359, 1-14.

Kameda, Y., Ito, M., Nishimaki, T., Gotoh, N., 2009. FRS2alpha is required for the separation, migration, and survival of pharyngeal-endoderm derived organs including thyroid, ultimobranchial body, parathyroid, and thymus. Dev Dyn 238, 503-513.

Kameda, Y., Nishimaki, T., Chisaka, O., Iseki, S., Sucov, H. M., 2007a. Expression of the epithelial marker E-cadherin by thyroid $\mathrm{C}$ cells and their precursors during murine development. $\mathrm{J}$ Histochem Cytochem 55, 1075-1088.

Kameda, Y., Nishimaki, T., Miura, M., Jiang, S. X., Guillemot, F., 2007b. Mash1 regulates the development of C cells in mouse thyroid glands. Dev Dyn 236, 262-270.

Kameda, Y., Nishimaki, T., Takeichi, M., Chisaka, O., 2002. Homeobox gene hoxa3 is essential for the formation of the carotid body in the mouse embryos. Dev Biol 247, 197-209. 
Kanai-Azuma, M., Kanai, Y., Gad, J. M., Tajima, Y., Taya, C., Kurohmaru, M., Sanai, Y., Yonekawa, H., et al., 2002. Depletion of definitive gut endoderm in Sox17-null mutant mice. Development 129, 2367-2379.

Kiehart, D. P., Galbraith, C. G., Edwards, K. A., Rickoll, W. L., Montague, R. A., 2000. Multiple forces contribute to cell sheet morphogenesis for dorsal closure in Drosophila. J Cell Biol 149, 471-490.

Kim, S. K., Melton, D. A., 1998. Pancreas development is promoted by cyclopamine, a hedgehog signaling inhibitor. Proc Natl Acad Sci U S A 95, 13036-13041.

Kimmel, C. B., Ballard, W. W., Kimmel, S. R., Ullmann, B., Schilling, T. F., 1995. Stages of embryonic development of the zebrafish. Dev Dyn 203, 253-310.

Kimura, J., Deutsch, G. H., 2007. Key mechanisms of early lung development. Pediatr Dev Pathol $10,335-347$.

Kimura, S., Hara, Y., Pineau, T., Fernandez-Salguero, P., Fox, C. H., Ward, J. M., Gonzalez, F. J., 1996. The T/ebp null mouse: thyroid-specific enhancer-binding protein is essential for the organogenesis of the thyroid, lung, ventral forebrain, and pituitary. Genes Dev 10, 60-69.

Kimura, S., Ward, J. M., Minoo, P., 1999. Thyroid-specific enhancer-binding protein/thyroid transcription factor 1 is not required for the initial specification of the thyroid and lung primordia. Biochimie 81, 321-327.

Kinebrew, G. M., Hilfer, S. R., 2001. Cellular dynamics during evagination of the thyroid primordium in the chick embryo. Anat Rec 264, 146-156.

Kirby, M. L., Gale, T. F., Stewart, D. E., 1983. Neural crest cells contribute to normal aorticopulmonary septation. Science 220, 1059-1061.

Kirby, M. L., Lawson, A., Stadt, H. A., Kumiski, D. H., Wallis, K. T., McCraney, E., Waldo, K. L., Li, Y. X., et al., 2003. Hensen's node gives rise to the ventral midline of the foregut: implications for organizing head and heart development. Dev Biol 253, 175-188.

Klein, A. H., Meltzer, S., Kenny, F. M., 1972. Improved prognosis in congenital hypothyroidism treated before age three months. J Pediatr 81, 912-915.

Knospe, C., Seichert, V., Rychter, Z., 1991. The topogenesis of the thyroid in chick embryos. Eur J Morphol 29, 291-296.

Korpal-Szczyrska, M., Kosiak, W., Swieton, D., 2008. Prevalence of thyroid hemiagenesis in an asymptomatic schoolchildren population. Thyroid 18, 637-639.

Kreisner, E., Camargo-Neto, E., Maia, C. R., Gross, J. L., 2003. Accuracy of ultrasonography to establish the diagnosis and aetiology of permanent primary congenital hypothyroidism. Clin Endocrinol (Oxf) 59, 361-365.

Krude, H., Schutz, B., Biebermann, H., von Moers, A., Schnabel, D., Neitzel, H., Tonnies, H., Weise, D., et al., 2002. Choreoathetosis, hypothyroidism, and pulmonary alterations due to human NKX2-1 haploinsufficiency. J Clin Invest 109, 475-480.

Kurihara, Y., Kurihara, H., Maemura, K., Kuwaki, T., Kumada, M., Yazaki, Y., 1995. Impaired development of the thyroid and thymus in endothelin-1 knockout mice. J Cardiovasc Pharmacol 26 Suppl 3, S13-16.

Kusakabe, T., Hoshi, N., Kimura, S., 2006. Origin of the ultimobranchial body cyst: T/ebp/Nkx2.1 expression is required for development and fusion of the ultimobranchial body to the thyroid. Dev Dyn 235, 1300-1309.

Lammert, E., Cleaver, O., Melton, D., 2001. Induction of pancreatic differentiation by signals from blood vessels. Science 294, 564-567.

Lania, G., Zhang, Z., Huynh, T., Caprio, C., Moon, A. M., Vitelli, F., Baldini, A., 2009. Early thyroid development requires a Tbx1-Fgf8 pathway. Dev Biol 328, 109-117.

Lawson, K. A., Pedersen, R. A., 1987. Cell fate, morphogenetic movement and population kinetics of embryonic endoderm at the time of germ layer formation in the mouse. Development $101,627-652$. 
Lazzaro, D., Price, M., de Felice, M., Di Lauro, R., 1991. The transcription factor TTF-1 is expressed at the onset of thyroid and lung morphogenesis and in restricted regions of the foetal brain. Development 113, 1093-1104.

Le Lievre, C. S., Le Douarin, N. M., 1975. Mesenchymal derivatives of the neural crest: analysis of chimaeric quail and chick embryos. J Embryol Exp Morphol 34, 125-154.

Lee, C. S., Friedman, J. R., Fulmer, J. T., Kaestner, K. H., 2005. The initiation of liver development is dependent on Foxa transcription factors. Nature 435, 944-947.

Lewis, S. L., Tam, P. P., 2006. Definitive endoderm of the mouse embryo: formation, cell fates, and morphogenetic function. Dev Dyn 235, 2315-2329.

Lien, C. L., Wu, C., Mercer, B., Webb, R., Richardson, J. A., Olson, E. N., 1999. Control of early cardiac-specific transcription of Nkx2-5 by a GATA-dependent enhancer. Development $126,75-84$.

Lindsay, E. A., Vitelli, F., Su, H., Morishima, M., Huynh, T., Pramparo, T., Jurecic, V., Ogunrinu, G., et al., 2001. Tbx1 haploinsufficieny in the DiGeorge syndrome region causes aortic arch defects in mice. Nature 410, 97-101.

Lough, J., Sugi, Y., 2000. Endoderm and heart development. Dev Dyn 217, 327-342.

Lu, J., Izvolsky, K. I., Qian, J., Cardoso, W. V., 2005. Identification of FGF10 targets in the embryonic lung epithelium during bud morphogenesis. J Biol Chem 280, 4834-4841.

Macatee, T. L., Hammond, B. P., Arenkiel, B. R., Francis, L., Frank, D. U., Moon, A. M., 2003. Ablation of specific expression domains reveals discrete functions of ectoderm- and endoderm-derived FGF8 during cardiovascular and pharyngeal development. Development 130, 6361-6374.

Macchia, P. E., Lapi, P., Krude, H., Pirro, M. T., Missero, C., Chiovato, L., Souabni, A., Baserga, M., et al., 1998. PAX8 mutations associated with congenital hypothyroidism caused by thyroid dysgenesis. Nat Genet 19, 83-86.

Maiorana, R., Carta, A., Floriddia, G., Leonardi, D., Buscema, M., Sava, L., Calaciura, F., Vigneri, R., 2003. Thyroid hemiagenesis: prevalence in normal children and effect on thyroid function. J Clin Endocrinol Metab 88, 1534-1536.

Manley, N. R., Capecchi, M. R., 1995. The role of Hoxa-3 in mouse thymus and thyroid development. Development 121, 1989-2003.

Manley, N. R., Capecchi, M. R., 1998. Hox group 3 paralogs regulate the development and migration of the thymus, thyroid, and parathyroid glands. Dev Biol 195, 1-15.

Mansouri, A., Chowdhury, K., Gruss, P., 1998. Follicular cells of the thyroid gland require Pax8 gene function. Nat Genet 19, 87-90.

Martin, A. C., Kaschube, M., Wieschaus, E. F., 2008. Pulsed contractions of an actin-myosin network drive apical constriction. Nature

Martinez Barbera, J. P., Clements, M., Thomas, P., Rodriguez, T., Meloy, D., Kioussis, D., Beddington, R. S., 2000. The homeobox gene Hex is required in definitive endodermal tissues for normal forebrain, liver and thyroid formation. Development 127, 2433-2445.

Matsumoto, K., Yoshitomi, H., Rossant, J., Zaret, K. S., 2001. Liver organogenesis promoted by endothelial cells prior to vascular function. Science 294, 559-563.

Medina-Martinez, O., Brownell, I., Amaya-Manzanares, F., Hu, Q., Behringer, R. R., Jamrich, M., 2005. Severe defects in proliferation and differentiation of lens cells in Foxe3 null mice. Mol Cell Biol 25, 8854-8863.

Michael, L., Davies, J. A., 2004. Pattern and regulation of cell proliferation during murine ureteric bud development. J Anat 204, 241-255.

Michael, L., Sweeney, D. E., Davies, J. A., 2005. A role for microfilament-based contraction in branching morphogenesis of the ureteric bud. Kidney Int 68, 2010-2018.

Minoo, P., Hamdan, H., Bu, D., Warburton, D., Stepanik, P., deLemos, R., 1995. TTF-1 regulates lung epithelial morphogenesis. Dev Biol 172, 694-698. 
Mittag, J., Winterhager, E., Bauer, K., Grummer, R., 2007. Congenital hypothyroid female pax8deficient mice are infertile despite thyroid hormone replacement therapy. Endocrinology 148, 719-725.

Moore-Scott, B. A., Manley, N. R., 2005. Differential expression of Sonic hedgehog along the anterior-posterior axis regulates patterning of pharyngeal pouch endoderm and pharyngeal endoderm-derived organs. Dev Biol 278, 323-335.

Morreale de Escobar, G., 2001. The role of thyroid hormone in fetal neurodevelopment. J Pediatr Endocrinol Metab 14 Suppl 6, 1453-1462.

Muratovska, A., Zhou, C., He, S., Goodyer, P., Eccles, M. R., 2003. Paired-Box genes are frequently expressed in cancer and often required for cancer cell survival. Oncogene 22, 7989-7997.

Muzza, M., Persani, L., de Filippis, T., Gastaldi, R., Vigone, M. C., Sala, D., Weber, G., Lorini, R., et al., 2008. Absence of sonic hedgehog (Shh) germline mutations in patients with thyroid dysgenesis. Clin Endocrinol (Oxf) 69, 828-829.

Nakada, C., Iida, A., Tabata, Y., Watanabe, S., 2009. Forkhead transcription factor foxe1 regulates chondrogenesis in zebrafish. J Exp Zoolog B Mol Dev Evol

Nogawa, H., Morita, K., Cardoso, W. V., 1998. Bud formation precedes the appearance of differential cell proliferation during branching morphogenesis of mouse lung epithelium in vitro. Dev Dyn 213, 228-235.

O'Rahilly, R., 1983. The timing and sequence of events in the development of the human endocrine system during the embryonic period proper. Anat Embryol (Berl) 166, 439-451.

Ogasawara, M., Satou, Y., 2003. Expression of FoxE and FoxQ genes in the endostyle of Ciona intestinalis. Dev Genes Evol 213, 416-419.

Ohuchi, H., Hori, Y., Yamasaki, M., Harada, H., Sekine, K., Kato, S., Itoh, N., 2000. FGF10 acts as a major ligand for FGF receptor $2 \mathrm{IIIb}$ in mouse multi-organ development. Biochem Biophys Res Commun 277, 643-649.

Olivieri, A., Stazi, M. A., Mastroiacovo, P., Fazzini, C., Medda, E., Spagnolo, A., De Angelis, S., Grandolfo, M. E., et al., 2002. A population-based study on the frequency of additional congenital malformations in infants with congenital hypothyroidism: data from the Italian Registry for Congenital Hypothyroidism (1991-1998). J Clin Endocrinol Metab 87, 557562.

Park, S. M., Chatterjee, V. K., 2005. Genetics of congenital hypothyroidism. J Med Genet 42, 379389.

Park, W. Y., Miranda, B., Lebeche, D., Hashimoto, G., Cardoso, W. V., 1998. FGF-10 is a chemotactic factor for distal epithelial buds during lung development. Dev Biol 201, 125134.

Parlato, R., Rosica, A., Rodriguez-Mallon, A., Affuso, A., Postiglione, M. P., Arra, C., Mansouri, A., Kimura, S., et al., 2004. An integrated regulatory network controlling survival and migration in thyroid organogenesis. Dev Biol 276, 464-475.

Pearse, A. G., 1969. The cytochemistry and ultrastructure of polypeptide hormone-producing cells of the APUD series and the embryologic, physiologic and pathologic implications of the concept. J Histochem Cytochem 17, 303-313.

Pearse, A. G., Carvalheira, A. F., 1967. Cytochemical evidence for an ultimobranchial origin of rodent thyroid C cells. Nature 214, 929-930.

Pearse, A. G., Polak, J. M., 1971. Neural crest origin of the endocrine polypeptide (APUD) cells of the gastrointestinal tract and pancreas. Gut 12, 783-788.

Pera, E. M., Kessel, M., 1998. Demarcation of ventral territories by the homeobox gene NKX2.1 during early chick development. Dev Genes Evol 208, 168-171.

Perl, A. K., Wert, S. E., Nagy, A., Lobe, C. G., Whitsett, J. A., 2002. Early restriction of peripheral and proximal cell lineages during formation of the lung. Proc Natl Acad Sci U S A 99, 10482-10487. 
Peters, H., Neubuser, A., Kratochwil, K., Balling, R., 1998. Pax9-deficient mice lack pharyngeal pouch derivatives and teeth and exhibit craniofacial and limb abnormalities. Genes Dev 12, 2735-2747.

Petryk, A., Anderson, R. M., Jarcho, M. P., Leaf, I., Carlson, C. S., Klingensmith, J., Shawlot, W., O'Connor, M. B., 2004. The mammalian twisted gastrulation gene functions in foregut and craniofacial development. Dev Biol 267, 374-386.

Plachov, D., Chowdhury, K., Walther, C., Simon, D., Guenet, J. L., Gruss, P., 1990. Pax8, a murine paired box gene expressed in the developing excretory system and thyroid gland. Development 110, 643-651.

Pohlenz, J., Dumitrescu, A., Zundel, D., Martine, U., Schonberger, W., Koo, E., Weiss, R. E., Cohen, R. N., et al., 2002. Partial deficiency of thyroid transcription factor 1 produces predominantly neurological defects in humans and mice. J Clin Invest 109, 469-473.

Polak, J. M., Pearse, A. G., Le Lievre, C., Fontaine, J., Le Douarin, N. M., 1974. Immunocytochemical confirmation of the neural crest origin of avian calcitonin-producing cells. Histochemistry 40, 209-214.

Postiglione, M. P., Parlato, R., Rodriguez-Mallon, A., Rosica, A., Mithbaokar, P., Maresca, M., Marians, R. C., Davies, T. F., et al., 2002. Role of the thyroid-stimulating hormone receptor signaling in development and differentiation of the thyroid gland. Proc Natl Acad Sci U S A 99, 15462-15467.

Puppin, C., D'Elia, A. V., Pellizzari, L., Russo, D., Arturi, F., Presta, I., Filetti, S., Bogue, C. W., et al., 2003. Thyroid-specific transcription factors control Hex promoter activity. Nucleic Acids Res 31, 1845-1852.

Puppin, C., Presta, I., D'Elia, A. V., Tell, G., Arturi, F., Russo, D., Filetti, S., Damante, G., 2004. Functional interaction among thyroid-specific transcription factors: Pax8 regulates the activity of Hex promoter. Mol Cell Endocrinol 214, 117-125.

Pyati, U. J., Look, A. T., Hammerschmidt, M., 2007. Zebrafish as a powerful vertebrate model system for in vivo studies of cell death. Semin Cancer Biol 17, 154-165.

Reifers, F., Walsh, E. C., Leger, S., Stainier, D. Y., Brand, M., 2000. Induction and differentiation of the zebrafish heart requires fibroblast growth factor 8 (fgf8/acerebellar). Development $127,225-235$.

Reiter, J. F., Kikuchi, Y., Stainier, D. Y., 2001. Multiple roles for Gata5 in zebrafish endoderm formation. Development 128, 125-135.

Rohr, K. B., Concha, M. L., 2000. Expression of nk2.1a during early development of the thyroid gland in zebrafish. Mech Dev 95, 267-270.

Romert, P., Gauguin, J., 1973. The early development of the median thyroid gland of the mouse. A light-, electron-microscopic and histochemical study. Z Anat Entwicklungsgesch 139, 319336.

Rorth, P., 2007. Collective guidance of collective cell migration. Trends Cell Biol 17, 575-579.

Rossi, J. M., Dunn, N. R., Hogan, B. L., Zaret, K. S., 2001. Distinct mesodermal signals, including BMPs from the septum transversum mesenchyme, are required in combination for hepatogenesis from the endoderm. Genes Dev 15, 1998-2009.

Sakiyama, J., Yamagishi, A., Kuroiwa, A., 2003. Tbx4-Fgf10 system controls lung bud formation during chicken embryonic development. Development 130, 1225-1234.

Sala, F. G., Curtis, J. L., Veltmaat, J. M., Del Moral, P. M., Le, L. T., Fairbanks, T. J., Warburton, D., Ford, H., et al., 2006. Fibroblast growth factor 10 is required for survival and proliferation but not differentiation of intestinal epithelial progenitor cells during murine colon development. Dev Biol 299, 373-385.

Schultheiss, T. M., Xydas, S., Lassar, A. B., 1995. Induction of avian cardiac myogenesis by anterior endoderm. Development 121, 4203-4214. 
Serls, A. E., Doherty, S., Parvatiyar, P., Wells, J. M., Deutsch, G. H., 2005. Different thresholds of fibroblast growth factors pattern the ventral foregut into liver and lung. Development 132, $35-47$.

Shabana, W., Delange, F., Freson, M., Osteaux, M., De Schepper, J., 2000. Prevalence of thyroid hemiagenesis: ultrasound screening in normal children. Eur J Pediatr 159, 456-458.

Shain, W. G., Hilfer, S. R., Fonte, V. G., 1972. Early organogenesis of the embryonic chick thyroid. I. Morphology and biochemistry. Dev Biol 28, 202-218.

Shiraishi, T., Imai, H., Fukutome, K., Watanabe, M., Yatani, R., 1999. Ectopic thyroid in the adrenal gland. Hum Pathol 30, 105-108.

Sinner, D., Rankin, S., Lee, M., Zorn, A. M., 2004. Sox17 and beta-catenin cooperate to regulate the transcription of endodermal genes. Development 131, 3069-3080.

Smuts, M. S., Hilfer, S. R., Searls, R. L., 1978. Patterns of cellular proliferation during thyroid organogenesis. J Embryol Exp Morphol 48, 269-286.

Spagnoli, F. M., 2007. From endoderm to pancreas: a multistep journey. Cell Mol Life Sci 64, 2378-2390.

Sprinzl, G. M., Koebke, J., Wimmers-Klick, J., Eckel, H. E., Thumfart, W. F., 2000. Morphology of the human thyroglossal tract: a histologic and macroscopic study in infants and children. Ann Otol Rhinol Laryngol 109, 1135-1139.

Stafford, D., Prince, V. E., 2002. Retinoic acid signaling is required for a critical early step in zebrafish pancreatic development. Curr Biol 12, 1215-1220.

Stanger, B. Z., Tanaka, A. J., Melton, D. A., 2007. Organ size is limited by the number of embryonic progenitor cells in the pancreas but not the liver. Nature 445, 886-891.

Strohschneider, T., Timm, D., Worbes, C., 1993. [Ectopic thyroid gland tissue in the liver]. Chirurg 64, 751-753.

Tam, P. P., Kanai-Azuma, M., Kanai, Y., 2003. Early endoderm development in vertebrates: lineage differentiation and morphogenetic function. Curr Opin Genet Dev 13, 393-400.

Tanaka, H., Yanagisawa, K., Shinjo, K., Taguchi, A., Maeno, K., Tomida, S., Shimada, Y., Osada, H., et al., 2007. Lineage-specific dependency of lung adenocarcinomas on the lung development regulator TTF-1. Cancer Res 67, 6007-6011.

Teillet, M. A., Ziller, C., Le Douarin, N. M., 2008. Quail-chick chimeras. Methods Mol Biol 461, 337-350.

Thomas, P. Q., Brown, A., Beddington, R. S., 1998. Hex: a homeobox gene revealing periimplantation asymmetry in the mouse embryo and an early transient marker of endothelial cell precursors. Development 125, 85-94.

Toublanc, J. E., 1992. Comparison of epidemiological data on congenital hypothyroidism in Europe with those of other parts in the world. Horm Res 38, 230-235.

Tourneux, J. E., Verdun, P., 1897. Sur les premièrs développements de la thyroide, du thymus et des glandules parathyroidennes chez l'hommes. J Anat 33, 305-325.

Tremblay, K. D., Zaret, K. S., 2005. Distinct populations of endoderm cells converge to generate the embryonic liver bud and ventral foregut tissues. Dev Biol 280, 87-99.

Waldo, K. L., Kumiski, D., Kirby, M. L., 1996. Cardiac neural crest is essential for the persistence rather than the formation of an arch artery. Dev Dyn 205, 281-292.

van den Brink, G. R., 2007. Hedgehog signaling in development and homeostasis of the gastrointestinal tract. Physiol Rev 87, 1343-1375.

Van Vliet, G., 2003. Development of the thyroid gland: lessons from congenitally hypothyroid mice and men. Clin Genet 63, 445-455.

Warga, R. M., Nusslein-Volhard, C., 1999. Origin and development of the zebrafish endoderm. Development 126, 827-838.

Washington Smoak, I., Byrd, N. A., Abu-Issa, R., Goddeeris, M. M., Anderson, R., Morris, J., Yamamura, K., Klingensmith, J., et al., 2005. Sonic hedgehog is required for cardiac outflow tract and neural crest cell development. Dev Biol 283, 357-372. 
Wells, J. M., Melton, D. A., 1999. Vertebrate endoderm development. Annu Rev Cell Dev Biol 15, 393-410.

Wells, J. M., Melton, D. A., 2000. Early mouse endoderm is patterned by soluble factors from adjacent germ layers. Development 127, 1563-1572.

Venditti, M., Hay, R. W., Kulaga, A., Demetrick, D. J., 2007. Diagnosis of ectopic tissue versus contamination by genetic fingerprinting in a routine surgical pathology specimen. Hum Pathol 38, 378-382.

Wendl, T., Adzic, D., Schoenebeck, J. J., Scholpp, S., Brand, M., Yelon, D., Rohr, K. B., 2007. Early developmental specification of the thyroid gland depends on han-expressing surrounding tissue and on FGF signals. Development 134, 2871-2879.

Wendl, T., Lun, K., Mione, M., Favor, J., Brand, M., Wilson, S. W., Rohr, K. B., 2002. Pax2.1 is required for the development of thyroid follicles in zebrafish. Development 129, 3751-3760.

Wessells, N. K., Sponner, B. S., Ash, J. F., Bradley, M. O., Luduena, M. A., Taylor, E. L., Wrenn, J. T., Yamada, K. M., 1971. Microfilaments in cellular and developmental processes. Science 171, 135-143.

Westerlund, J., Andersson, L., Carlsson, T., Zoppoli, P., Fagman, H., Nilsson, M., 2008. Expression of Islet1 in thyroid development related to budding, migration, and fusion of primordia. Dev Dyn 237, 3820-3829.

Wetzel, B. K., Wollman, S. H., 1969. Fine structure of a second kind of thyroid follicle in the C3H mouse. Endocrinology 84, 563-578.

Wheelock, M. J., Shintani, Y., Maeda, M., Fukumoto, Y., Johnson, K. R., 2008. Cadherin switching. J Cell Sci 121, 727-735.

Williams, R. J., Lindop, G., Butler, J., 2002. Ectopic thyroid tissue on the ascending aorta: an operative finding. Ann Thorac Surg 73, 1642-1643.

Wistuba, J., Mittag, J., Luetjens, C. M., Cooper, T. G., Yeung, C. H., Nieschlag, E., Bauer, K., 2007. Male congenital hypothyroid Pax8-/- mice are infertile despite adequate treatment with thyroid hormone. J Endocrinol 192, 99-109.

Vitelli, F., Taddei, I., Morishima, M., Meyers, E. N., Lindsay, E. A., Baldini, A., 2002. A genetic link between Tbx1 and fibroblast growth factor signaling. Development 129, 4605-4611.

Wurdak, H., Ittner, L. M., Sommer, L., 2006. DiGeorge syndrome and pharyngeal apparatus development. Bioessays 28, 1078-1086.

Xing, Y., Li, C., Hu, L., Tiozzo, C., Li, M., Chai, Y., Bellusci, S., Anderson, S., et al., 2008. Mechanisms of TGFbeta inhibition of LUNG endodermal morphogenesis: The role of TbetaRII, Smads, Nkx2.1 and Pten. Dev Biol

Xu, P. X., Zheng, W., Laclef, C., Maire, P., Maas, R. L., Peters, H., Xu, X., 2002. Eya1 is required for the morphogenesis of mammalian thymus, parathyroid and thyroid. Development 129, 3033-3044.

Yanagisawa, H., Hammer, R. E., Richardson, J. A., Williams, S. C., Clouthier, D. E., Yanagisawa, M., 1998. Role of Endothelin-1/Endothelin-A receptor-mediated signaling pathway in the aortic arch patterning in mice. J Clin Invest 102, 22-33.

Yoshitomi, H., Zaret, K. S., 2004. Endothelial cell interactions initiate dorsal pancreas development by selectively inducing the transcription factor Ptf1a. Development 131, 807-817.

Yu, J. K., Holland, L. Z., Jamrich, M., Blitz, I. L., Hollan, N. D., 2002. AmphiFoxE4, an amphioxus winged helix/forkhead gene encoding a protein closely related to vertebrate thyroid transcription factor-2: expression during pharyngeal development. Evol Dev 4, 9-15.

Zannini, M., Avantaggiato, V., Biffali, E., Arnone, M. I., Sato, K., Pischetola, M., Taylor, B. A., Phillips, S. J., et al., 1997. TTF-2, a new forkhead protein, shows a temporal expression in the developing thyroid which is consistent with a role in controlling the onset of differentiation. Embo J 16, 3185-3197. 
Figure 1

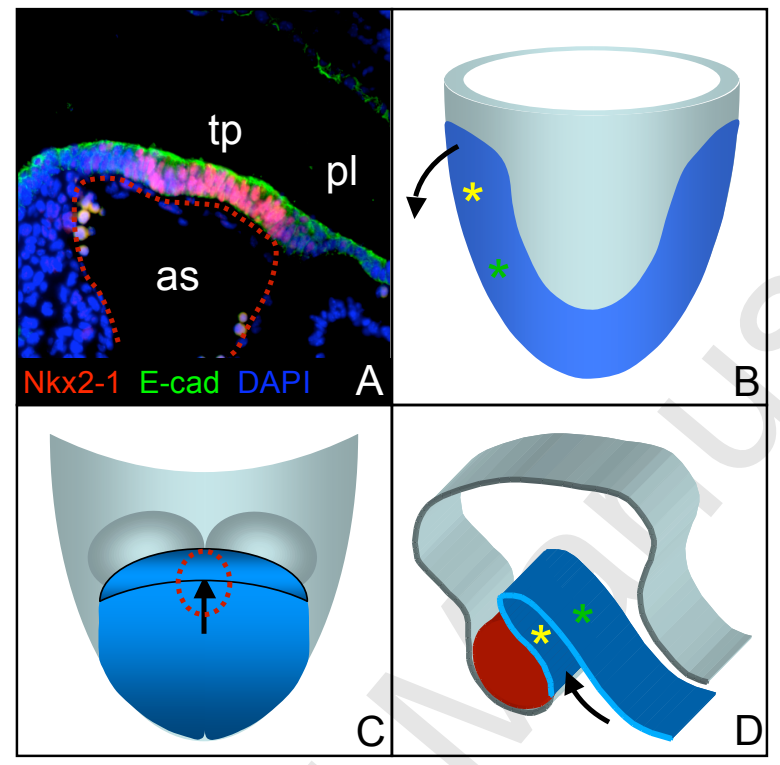

Page 66 of 68 
Figure 2
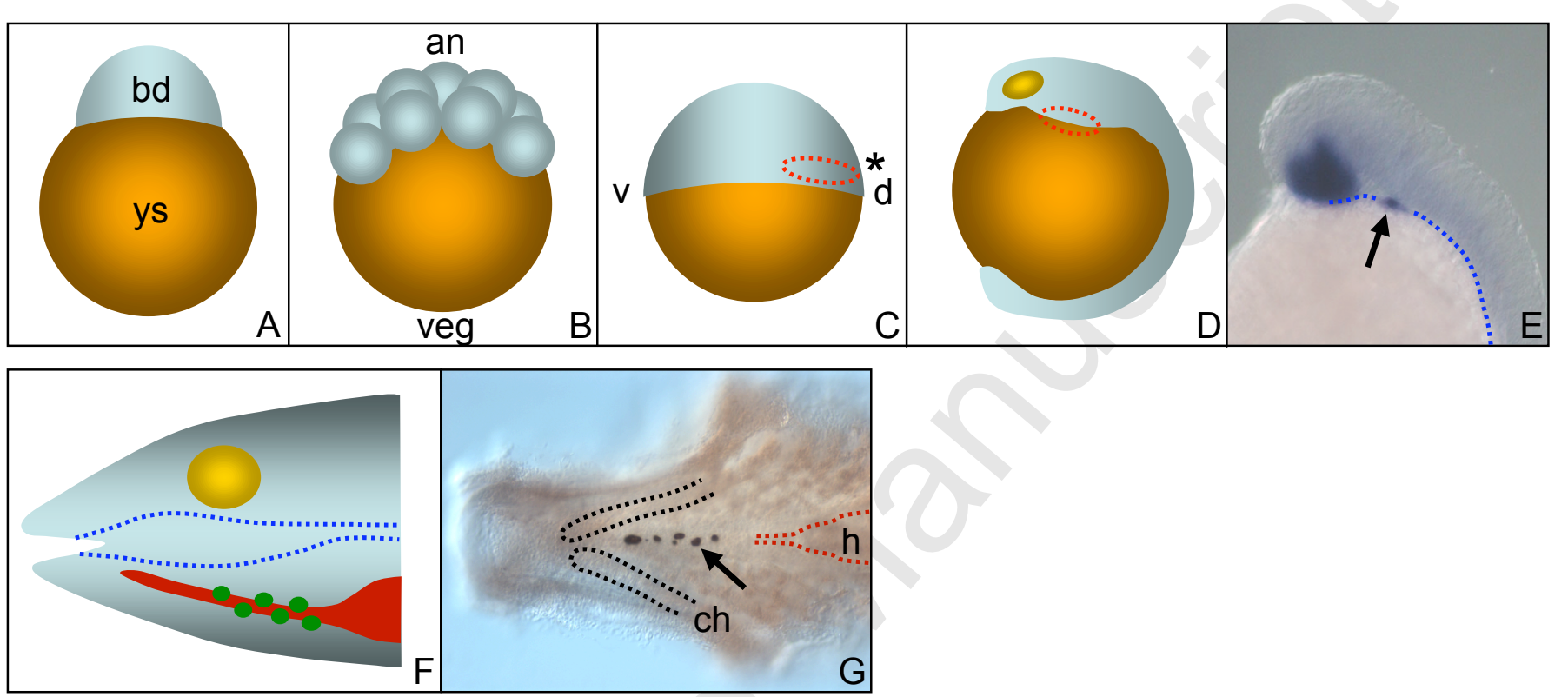
Figure 3

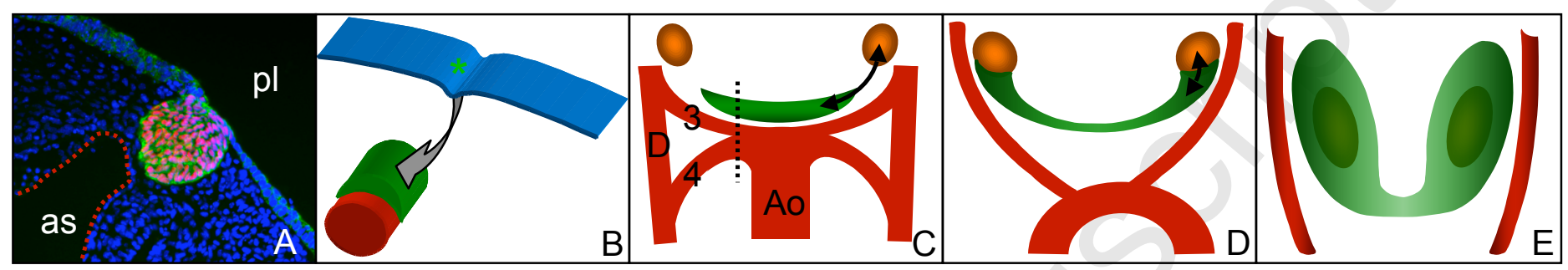

Page 68 of 68 